\title{
Cambios en las relaciones laborales y en el trabajo en Colombia, un inicio de siglo con transformaciones
}

\author{
López Pino, Carmen Marina*
}

\section{Resumen}

Este artículo estudia los cambios en las relaciones laborales y en el trabajo acaecidos a finales del siglo pasado y principios del siglo XXI, en la industria colombiana. Teóricamente se apoya en el marco analítico propuesto por el equipo del M.I.T. basado en las "opciones estratégicas de los actores", y metodológicamente aborda el estudio a través de seis estudios de caso, empleando técnicas cualitativas como la observación no participante, la entrevista semi-estructurada a los actores empresariales (directivos, trabajadores y sindicatos) y análisis documental. La conclusión a la que llega el estudio es, por un lado, valida la pertinencia del marco analítico propuesto por el M.I.T. en el estudio de las relaciones laborales, en el sentido de darle un papel central a la empresa como unidad de análisis y a las estrategias de los actores empresariales. Sin embargo, la autora llama la atención de la necesidad de incorporar en este marco analítico la esfera política, para una adecuada interpretación de la construcción de las mentalidades empresariales. Por otro lado, constata el papel que ha jugado la estrategia de la calidad total-jat en la transformación de las relaciones laborales y del trabajo en los estudios de caso analizados.

Palabras clave: Relaciones laborales, trabajo, industria colombiana.

\section{Changes in Labor Relations and Work in Colombia: Starting a Century With Transformations}

\section{Abstract}

This article studies the changes in labor relations and work that occurred at the end of the past and the beginning of the $21^{\text {st }}$ centuries, in Colombian industry. In terms of theory, it draws on the analytical framework proposed by the M.I.T. team based on the "strategic options of the actors;" methodologically, it approaches the topic through six case studies, using qualitative techniques such as nonparticipative observation, the semi-structured interview of business actors (directors, workers and la-

Recibido: 08-02-07. Aceptado: 02-07-07

Socióloga y economista, Doctora en sociología por la Universidad Complutense de Madrid, docente-investigadora Escuela de Ciencias Humanas, Universidad del Rosario, Bogotá, Colombia. 
bor union representatives) and documentary analysis. On one hand, conclusions validate the pertinence of the analytic framework proposed by M.I.T. in the study of labor relations, in the sense of giving a central role to the company as a unit for analysis and to the strategies of the business actors. Nevertheless, the author calls attention to the need for incorporating the political sphere in this framework, in order to obtain an adequate interpretation of the construction of business mentalities. On the other hand, it verifies the role that total quality strategy has played in transforming labor relations and work in the case studies analyzed.

Key words: Labor relations, work, Colombian industry.

\section{Introducción}

El siglo XXI inicia con significativos cambios en las relaciones laborales y en el trabajo en Colombia. La crisis económica de final de siglo, la apertura de los mercados y la recomposición del movimiento obrero colombiano, son elementos que explican dichos cambios. Si bien, estos elementos contextuales juegan un papel importante en estas transformaciones, en este artículo se plantea que la gestión de la calidad total-JAT, como estrategia empresarial, jugó un papel importante, y que sus efectos dependieron de la mentalidad de los empresarios respecto a las organizaciones sindicales, de las relaciones laborales previamente existentes en las empresas y de las estrategias individuales y colectivas de los trabajadores.

Para la interpretación y explicación de dichos cambios, la investigación tomó como marco analítico la propuesto del equipo del M.I.T. (Massachussets Institute of Technology ${ }^{1}$, que da especial énfasis a las opciones estratégicas de los actores. Por ello, primero, centró la investi- gación en la empresa y, segundo, tomó como objeto material la implementación de la estrategia empresarial de la Gestión de la Calidad-JAT, que incide directamente en la organización del trabajo, en las relaciones de trabajo y en consecuencia en las relaciones laborales.

El equipo del M.I.T. se distancia de la tradición de los investigadores europeos que según Kochan et al.:

“... hace hincapié en la importancia de la influencia restrictiva ejercida por las estructuras establecidas (los mecanismos institucionales, incluidos los órganos y normas laborales), que limitan la libertad de acción individual de las empresas y de los demás actores en el campo de las relaciones de trabajo. Según esta hipótesis, la orientación que caracteriza al M.I.T. exagera la importancia de la empresa como unidad de análisis, y por esa razón descuida los factores que en países con sistemas de relaciones de trabajo más centralizados contribuyen a moldear desde afuera las prácticas de empleo en los centros de trabajo" (1995: 161).

1 Pertenecen a esta escuela investigadores como Thomas Kochan, Michael Piore, Harriz Katz, Robert MacKersie, Michael Useem, Paul Osterman, Richard Locke, Russell Lansbury y John Paul MacDuffie, entre otros. 


\section{Optamos por el marco analítico del} M.I.T. porque, aunque en dimensiones muy diferentes, en Estados Unidos ${ }^{2}$ como en Colombia, la empresa juega un papel analítico relevante en la definición de las relaciones laborales a nivel micro, debido a la poca institucionalización de un sistema de relaciones laborales (Estado-empresas-sindicatos) que brinde un marco para la configuración de las relaciones laborales en las empresas. Este sistema constituye un punto central en el análisis del poder y de la regulación de las relaciones y condiciones de trabajo en los países industrializados europeos. Sus elementos básicos son la normatividad estatal sobre los derechos laborales individuales y colectivos, la negociación colectiva y las instituciones de representación e intereses (comp. Poole, 1986: 31).

En países como Colombia las estructuras institucionales de vinculación de las conductas micro, representadas por el sistema de relaciones laborales, son frágiles y no regulan de manera suficiente las relaciones dentro de las empresas lo que genera una diversidad de formas de relaciones laborales poco favorables al orden social y a la democratización de las condiciones contractuales y laborales de los trabajadores ${ }^{3}$. En este sentido, la débil institucionalización del nivel meso, representado por la interacción Estado, empresarios y trabajadores, propicia una mayor discrecionalidad empresarial.

Esta discrecionalidad empresarial fue favorecida por un contexto proteccionista, en el cual las empresas no tuvieron mayores presiones en cuanto a competencias de mercados externos, sumado a la consolidación de un entramado empresarial muy heterogéneo cuyo papel relevante fue ejercido por empresas monopólicas y oligopólicas; y a un ámbito político y económico poco favorable a la presencia de los sindicatos en los espacios empresariales.

La argumentación básica del M.I.T. es que las prácticas y resultados de las relaciones laborales se configuran en las interacciones del entorno, así como en las

Kochan, Katz y MacKersie (1993), en su investigación "La transformación de las relaciones laborales en los Estados Unidos", se apoyan en la obra de Alfred Chander, Strategy and Structure (1966), para explicar las relaciones entre estrategia y estructura y entre estructuras de gestión y políticas de relaciones laborales de las empresas. Para el análisis del concepto de estrategia se retoma dicho texto y The visible Hand (1977) del mismo autor.

3 Lamo de Epinosa (1996:85) se cuestiona lo siguiente: “¿De qué depende que el orden genere orden o al contrario? ¿De qué depende el acoplamiento/desacoplamiento de niveles? Depende de que haya o no estructuras de vinculación de las acciones, de que la masa agregada de los sujetos sea o no un sistema, de la interdependencia definitiva entre las partes lo que permite el cambio de la cantidad en cualidad, el salto desde el orden al desorden, o viceversa, el desacoplamiento de los niveles. Por expresarlo en lenguaje clásico de Durkheim: “... el acoplamiento/desacoplamiento de lo micro y lo macro depende del nivel meso, del nivel intermedio de vinculación. Si el nivel meso es fuerte, si hay numerosas y profundas estructuras institucionales de vinculación, la impredecibilidad de la conducta micro no se traduce en una simétrica impredecibilidad del orden agredagado. Y viceversa, en ausencia de una fuerte institucionalización meso, el orden micro no genera orden macro sino desorden macro....". 
decisiones estratégicas y la escala de valores de los empresarios, dirigentes sindicales, trabajadores y autoridades públicas (Kochan, 1993: 25). Considera las historias nacionales y locales, en especial las mentalidades de los empresarios construidas históricamente, como elementos fundamentales de su análisis. Desde esta perspectiva, las estrategias de los empresarios están permeadas por su opinión sobre las organizaciones sindicales. Es así como los directivos empresariales responden al entorno exterior orientados por este sistema de valores (Kochan, 1993:37) ${ }^{4}$. En este sentido, la estrategia de la calidad total-jat estaría filtrada por la red de instituciones existentes a nivel micro y macro y por la mentalidad empresarial respecto al papel de las organizaciones sindicales en la configuración de las relaciones laborales y del trabajo.

La idea es corroborar la pertinencia de esta propuesta analítica para la com- prensión y explicación de los cambios en las relaciones laborales y en el trabajo en la industria colombiana, siendo el objeto material la gestión de la calidad total-jat. Con miras a desentrañar en qué consisten estos cambios se optó por una metodología cualitativa, a través de seis estudios de caso. La selección de las empresas tuvo un carácter bipolar, tres de ellas con una tradición de relaciones denominadas antagónicas entre capital y trabajo y tres bajo relaciones neopaternalistas (López, 1999: 193-221). De las cuales cuatro contaban con sindicato y dos estaban regidas bajo la figura del pacto colectivo. ${ }^{5}$ En todas ellas, los empresarios asumieron, como estrategia empresarial, la implementación de diversas herramientas de la gestión de la calidad total-jat. Se adelantaron técnicas tales como: observación no participante, análisis documental y entrevistas semi-estructuradas. Estas últimas se llevaron a cabo con perso-

$4 \quad$ El modelo de relaciones laborales del New Deal se convirtió en la forma dominante de negociación colectiva después de la Segunda Guerra Mundial y hasta los años setenta. Marcó la pauta en la gestión de los recursos humanos, incluso en los lugares donde los sindicatos no habían adquirido todavía derechos de representación. Varios fueron los rasgos de nivel estratégico del sistema de relaciones laborales del New Deal. Primero, la previsión de que los empresarios aceptarían pragmáticamente la negociación colectiva. Segundo, el principio de que a cambio de la aceptación del papel de los sindicatos en la determinación de los salarios, horarios y condiciones de trabajo, los empresarios mantendrían la iniciativa en las decisiones empresariales y en las acciones a nivel de fábrica. Tercero, la formación de un sindicalismo interesado por el "control de las condiciones laborales" que permitiría el establecimiento de convenios y procedimientos, muy estructurados, para resolver judicialmente las diferencias surgidas durante la vigencia de los contratos. De acuerdo con este sistema, los derechos y obligaciones de los trabajadores estaban vinculados a puestos de trabajo rigurosamente desarrollados y con una configuración muy detallada (Kochan, et al., 1993).

No obstante, para Kochan et al. (1993), el consenso entre empresarios, trabajadores y gobierno no siempre supuso el abandono de una 'ideología' poco favorable a la presencia de los sindicatos en los ámbitos empresariales. Este consenso fue el resultado de una estrategia pragmática de los empresarios que fue bien recibida por los trabajadores y que contó con el respaldo de las entidades gubernamentales. 
nal directivo, ingenieros, supervisores, trabajadores y representantes sindicales. En algunas ocasiones se entrevistó a personas retiradas.

El artículo está integrado por los siguientes apartados: primero, se expone brevemente los fundamentos del la gestión de la calidad total-JAT; segundo, el contexto de la industria colombiana; tercero, la transformación de las relaciones laborales; cuarto, los cambios en el trabajo; y quinto, las conclusiones.

Veamos de manera sucinta en qué consiste teóricamente dicha estrategia empresarial.

\section{La gestión de la calidad total-jat como estrategia}

Producir y entregar bienes terminados justo en el momento de ser vendidos y libres de defectos, supone un cambio de paradigma (taylorismo-fordismo), lo que algunos atinan a llamar una "revolución mental", que tiene fuertes implicaciones en los roles de la gerencia, de los mandos medios y de los trabajadores; en los métodos y flujos de trabajo; en la distribución del espacio; en el sentido del tiempo y de la información; en las relaciones con los proveedores y consumidores; y una orientación hacia el mejoramiento continuo. Esto supone una organización "ma- gra", "flexible" que procura descentralizar o externalizar funciones o actividades consideradas innecesarias, pero realizadas por una red de empresas.

En su objetivo por alcanzar la máxima rentabilidad del capital la estrategia de la Gestión de la Calidad Total-jat presenta dos grandes formas de racionalización, una marcadamente formal orientada a una mayor racionalidad de los procesos, entendida como mayor control y calculabilidad sobre los mismos; y a una reducción de la incertidumbre y riesgo a través de programas de autocontrol y de mejoramiento continuo; todo ello con miras a hacer de las empresas organizaciones sistémicas, integradas funcionalmente, intercomunicadas y en permanente cambio. Aquí la racionalidad no va a ser entendida en términos de Taylor como una racionalidad estática, basada en la jerarquización de la autoridad, división funcional de departamentos, especialización de la mano de obra y estandarización de los procesos; sino una racionalidad dinámica sustentada en una organización flexible, cuyo ethos es el mejoramiento continuo basado en la disposición de la mano de obra al autocontrol y al mejoramiento, desestimando el simple cumplimiento de las tareas asignadas. Otra, complementaria a ésta, apoyada en una racionalidad material, que acude a la

EI Pacto colectivo es una figura jurídica que reemplaza la negociación sindical por un pacto establecido entre la dirección empresarial y los trabajadores, excluyendo al actor sindical. Legalmente el empresario puede convocar a la firma de un Pacto Colectivo cuando el porcentaje de sindicalización es inferior a una tercera parte de total del personal ocupado en dicha empresa. Esta figura surge de un contrapliego patronal y cada vez goza de más peso en Colombia, de tal manera que en 1990 ante el Ministerio de Seguridad Social y Trabajo se presentaron 117 pactos y 231 convenciones colectivas, lo que representa el $34 \%$ y $66 \%$, respectivamente. 
motivación, participación, compromiso e integración de los trabajadores a la empresa para alcanzar de manera conjunta el fin empresarial, el cual es planteado como un fin colectivo, único, distante de tensiones y contradicciones. De ahí que se propugne por relaciones directas entre capital y trabajo, "cara a cara", sin requerir la mediación sindical.

Esta doble racionalidad de la estrategia de la calidad-jat se ajusta a los intereses de la dirección empresarial colombiana, en un doble sentido. Por un lado, aparece como la alternativa más idónea en términos de eficiencia y eficacia empresarial, es decir, acorde a los actuales principios de racionalidad formal. Y por otro lado, se ajusta a la ideología empresarial colombiana poco favorable a la presencia de los sindicatos en los ámbitos empresariales. De ahí que la investigación plantee que la introducción de la gestión de la calidad total-jat, no sólo responde a una estrategia productiva en términos de rendimientos sino a una estrategia política, orientada a debilitar el poder de las organizaciones sindicales en el interior de las empresas, o en su defecto, a excluirlos como actores válidos en la contienda empresarial, si se cuenta con recursos de poder y la coyuntura histórica lo permite.

La puesta en marcha de estas dos formas de racionalización suponen primero, la disposición de los actores para asumir dichos cambios; segundo, el desmoronamiento de instituciones, prácticas de gestión y relaciones sociales existentes en las fábricas, que al comprometer intereses y costumbres, transforman las relaciones laborales y el trabajo; tercero, un contexto económico y político favora- ble para la implementación de forma coherente de dicha estrategia de gestión.

\section{Breve contextualización de la industria colombiana}

La crisis económica de los años ochenta y posterior apertura de los mercados desveló una estructura industrial tecnológicamente atrasada y dependiente, muy concentrada y heterogénea, con bajos niveles de productividad; apoyada en bienes de consumo e intermedios y orientada al mercado interno; sustentada en una gestión empresarial ineficiente y poco innovadora, frágil para resistir no sólo la competencia de productos externos sino para enfrentar un entorno económico agresivo e incierto (Garay, et al., 1998). La situación se agravó por la ausencia de sólidas instituciones económicas, políticas y sociales, que posibilitaran a los actores empresariales orientar y fundar estrategias.

La crisis de los años ochenta estuvo acompañada de la llegada de algunas herramientas de gestión, que posteriormente se conocerían como componentes de la Gestión de la Calidad Total-JAT (Weiss, 1997; López, 1993). En un primer momento, las empresas pioneras centran los cambios en el empleo de herramientas participativas, círculos de calidad, grupos de mejoramiento, a la par que hacen esfuerzos por una mayor estandarización y normalización de los procesos. Para la década del noventa, ya existe una mayor claridad sobre la gestión de la calidad total-jat y las empresas que se orientan por esta estrategia van a dar un giro hacia una reestructuración sistémica y de procesos, sin abandonar las herramien- 
tas participativas. Esto supone adelantar esfuerzos en torno a la producción acorde a las necesidades del mercado, aplanamiento de las estructuras administrativas, intercomunicación entre los diferentes departamentos, reestructuración física de las plantas, trabajo en grupo, autocontrol, mantenimiento productivo total, todo ello en procura de hacer de la empresa una organización sistémica con reducidos inventarios y una disposición hacia el mejoramiento continuo. Propósitos cumplidos en unas empresas más que en otras, y no siempre de manera coherente.

En el primer quinquenio de los noventa, a pesar de la crisis, las empresas más importantes o de punta en el sector 0 subsector guardan cierta esperanza en el futuro $y$, en gran parte, atribuyen a la estrategia de la Gestión de la Calidad Total-jat las probabilidades de permanencia e integración al mercado. Al final del siglo, la industria entra en una fase recesiva que lleva a algunas empresas a suspender temporalmente algunas de estas herramientas y dar paso a una estrategia de costos de mano de obra que entra en franca contradicción con una estrategia de motivación apoyada en relaciones de confianza entre empresarios y trabajadores. La demanda cae persistentemente y la incertidumbre se traduce en cierre de empresas, despidos y en aumento de la temporalidad laboral.

Según cifras del DANE, entre 1997 y 2002 el $18 \%$ de los establecimientos industriales son cerrados, es decir, 1.439; el $16 \%$ de la mano de obra ocupada es despedida; mientras los contratos temporales crecen en un $133 \%$. A partir del 2003, muy lentamente, la industria inicia un período de crecimiento, mientras las condiciones de trabajo desmejoran. Entre 2000 y 2003 la industria tiene un crecimiento del $6 \%$, aunque su participación en el PIB disminuye entre 1990 y 2000 , al pasar de 16,3\% a 14,4\% (Ventura, 2003: 43-44). Entre 1997 y 2004 los empleos temporales crecen en un $211 \%$ respecto a 1997, favorecido por las reformas laborales de 1990 y 2002, las cuales brindan condiciones para la flexibilización externa de la mano de obra (ver Gráfico 1). El siglo comienza con una importante reducción y precarización de la mano de obra que supone la ampliación de la brecha entre crecimiento de la producción y el empleo. Situación preocupante dada la débil capacidad de la economía formal para integrar la fuerza de trabajo en forma asalariada. Según el Dane, para 2005 el $59 \%$ de la población ocupada se encontraba en el sector informal.

La crisis empresarial no sólo afecta al capital sino al conjunto del sindicalismo del sector privado. El sector industrial pierde capacidad de convocatoria y es marginado de las grandes decisiones de la dirección nacional del sindicalismo. "No es una causalidad que de los 21 miembros del Comité Ejecutivo de la CUT elegidos en 2002, sólo uno de ellos represente al sector industrial y dos a la agroindustria (Delgado, 2003:7). Prueba de la debilidad de este sector fue la indiferencia con la cual el movimiento sindical observó como los sindicatos de empresas cementeras, automotrices, caucho, plásticos, palmas oleaginosas, fueron marginados. Ejemplos como los de Sofasa, Colmotores, Textiles Rio Negro, Avianca, Bavaria, Coltejer, Fabricato y Tejicondor son algunos de ellos (Cárdenas, 2006: 245). 


\section{Gráfico 1 \\ Total personal remunerado, permanente y temporal, industria Colombia, 1997-2004}

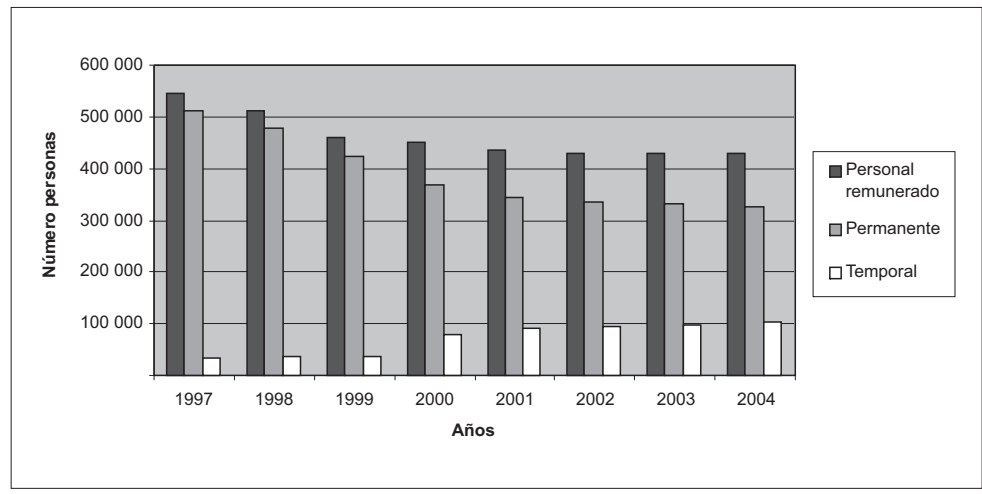

Fuente: DANE, 2005, Encuesta Manufacturera, Bogotá.

La internacionalización de los mercados, las innovaciones técnicas y organizativas, sumadas a reformas laborales orientadas a flexibilizar la mano de obra, han generado en importantes empresas colombianas cambios "fundamentales y estructurales" esto significa, expresado en términos de Kochan, et al., que "Ios papeles desempeñados por trabajadores y empresarios se han alejado de las pautas tradicionales hasta el punto de que no sólo modifican en forma cualitativa el proceso y los resultados de las negociaciones, sino que, además, cambian los papeles y estrategias de las partes en los niveles de las interacciones entre Estado, empresarios y organizaciones sindicales y de los centros de trabajo" (1993: 160). Nuestra hipótesis de trabajo es que estas transformaciones están articuladas a la estrategia de la gestión de la calidad total-jat, no obstante, que la introducción de las diversas herramientas hayan tenido matices diferentes a través del tiempo y de que carezcan, en algunos casos, de coherencia técnica y continuidad.

\section{La estrategia de la gestión de la calidad-jat y cambio en las relaciones laborales y en el trabajo}

Los cambios acaecidos en las empresas estudiadas están asociados a la gestión de la calidad-jat, y la continuidad y coherencia de esta estrategia lo está a su vez a la estabilidad económica y financiera de las empresas. Es de destacar también que las relaciones laborales previamente existentes en los contextos empresariales, las mentalidades de los empresarios sobre las organizaciones sindicales y las estrategias elaboradas individual y colectivamente por los trabajadores, filtran dicha estrategia, generando diversas transformaciones a nivel micro; de ahí la necesidad de establecer un puente entre el actor y las instituciones macro y micro. 
A comienzos del presente siglo tres ámbitos habían sido trastocados en las empresas estudiadas: 1) la estructura de la gestión; 2) las "formas de relaciones laborales" y 3) las formas de trabajo. Nos detendremos fundamentalmente en estos dos últimos aspectos.

\subsection{Las transformaciones en las "formas de relaciones laborales"}

La frágil institucionalización del nivel meso, representado por el sistema de relaciones laborales, favorece una mayor discrecionalidad empresarial. Pero esta particularidad del caso colombiano, está determinada, en parte, por el ámbito de la política, por esta razón se consideró de vital importancia para la explicación y comprensión de las relaciones laborales, a pesar de ser un aspecto poco estimado en el marco analítico del M.I.T.

La política es el espacio de los fines, es allí donde se construyen colectivamente los proyectos sociales y políticos deseables por una sociedad o grupos sociales en un momento histórico determinado. Es, en últimas, el espacio de construcción y validación de las ideologías que en la esfera material o en la del trabajo filtran las estrategias tanto de los empresarios como de los trabajadores; la política los provee de representaciones mutuas y de alguna manera de comportamientos sociales esperables, elementos de gran importancia para el despliegue de las estrategias.

Como en muchos países latinoamericanos, en Colombia la ideología de lucha de clases acompañó el surgimiento, consolidación y quebrantamiento del movimiento obrero colombiano. La exclu- sión de la izquierda del ámbito institucional de lo político coadyuvó a la formación de una izquierda no democrática (López de la Rocha, 1994) y de una elite empresarial que privilegiaba el enfrentamiento más que la concertación, poco dispuesta a respetar los acuerdos y a aceptar la existencia de intereses comunes sobre la base del reconocimiento de intereses diferentes entre las partes. Este contexto de frágiles espacios democráticos tuvo como consecuencia que, en apariencia, las fronteras entre sindicatos y organizaciones políticas de izquierda -incluyendo la guerrilla- se diluyeran y eso, a su vez, justificó socialmente acciones empresariales autoritarias y antisindicales que buscaban restarle validez a la lucha obrera y al conflicto mismo. La poca institucionalización de las negociaciones colectivas se expresa en la baja tasa de sindicalización de los trabajadores asalariados, la cual no supera el $5 \%$.

Colombia es uno de los países con más trabajadores sindicalizados asesinados en el mundo. Según la base de datos de la Escuela Nacional Sindical, desde 1991 hasta enero de 2005, habían asesinado 2.153 trabajadores. En los últimos años esta situación se ha agravado debido a que los sindicalistas están en la punta de mira de los grupos paramilitares $y$, en algunos casos, de la guerrilla, restando capacidad de acción a las organizaciones sindicales.

El ámbito político ha jugado un papel clave en la configuración de las mentalidades de los actores empresariales y de las formas de relaciones laborales configuradas en las empresas, bien por la presencia activa de actores externos que provienen de él o porque las organizacio- 
nes sindicales sufren el influjo indirecto de los partidos sobre sus tácticas y estrategias de lucha. Pero también porque ha provisto, tanto a empresarios como a trabajadores, de una construcción social del otro que toma forma y se materializa en el trabajo mismo, en las relaciones sociales y las instituciones internas. Es el ámbito en donde se institucionaliza ideologías poco favorables a los sindicatos. Es así como el entorno de lo político configura las relaciones laborales - $y$ a la vez es configurado por ellas-; en esa medida tendría que ser considerado teórica y empíricamente por los estudios sobre las relaciones laborales.

\section{- Política de reducción de costos: una estrategia económica y políti- ca}

La primera hipótesis de trabajo de esta investigación se basaba en la siguiente afirmación: en la medida en que la implementación de esta estrategia empresarial requería de determinadas condiciones institucionales y sociales internas, su repercusión en las relaciones laborales dependería de la forma de relaciones laborales existente. Ordenes laborales apoyados en relaciones de baja confianza entre empresa y trabajadores y en rígidos compromisos contractuales y organizativos entre trabajadores y empresa, serían poco propicios a la gestión de calidad-jat, por lo tanto era previsible una repercusión significativa -directa o indirecta- sobre las relaciones laborales, el caso extremo sería el de las relaciones antagónicas. Al contrario, órdenes sociales que gozaran de una amplia discrecionalidad empresarial y que se apoyaran en ciertas políticas de corresponsabilidad empresarial podrian verse reforzados con su implementación, caso las relaciones neopatemalistas.

La segunda hipótesis de trabajo planteaba que la repercusión de la gestión de la calidad en las relaciones laborales también está determinada por las estrategias de los trabajadores y sus organizaciones sindicales.

En las empresas estudiadas, caracterizadas por relaciones antagónicas, se observa que la implementación de la estrategia de la calidad total-jat estuvo antecedida, en unas empresas más que en otras, por la transformación previa de dichas relaciones laborales como condición estructural para la implementación de la gestión de la calidad-jat.

"Con relaciones laborales antagónicas entre capital-trabajo las relaciones de choque y la declaración de hostilidades son las que determinan las formas de lucha del sindicato, que para sus acciones se apoya en la movilización de las masas y en grupos políticos externos a la empresa. Por su parte, la dirección empresarial también asume una posición radical, no acepta la existencia de intereses diferentes a los suyos. El discurso de la unidad de intereses asumido, de una u otra forma, por los directivos empresariales que buscan erradicar al "enemigo interno", es tan radical como el del enemigo de clase enarbolado por el sindicato (López, 2002).

Los acuerdos sobre intereses comunes y diferentes y el respeto a los procedimientos y mecanismos de negociación son frágiles; ambas partes hacen uso instrumental de las instituciones legales y las abandonan para ganar más terreno si la situación cambia. Mientras la 
empresa, haciendo uso de su poder, emprende acciones autoritarias, el sindicato moviliza las masas y hace explícita la potencialidad de las acciones de hecho para defender los acuerdos establecidos formal o informalmente" (López, 2002).

Bajo este tipo de relaciones es difícil adelantar la estrategia de la gestión de la calidad apoyada en relaciones de confianza entre capital y trabajo; y más aún, cuando su implementación supone el abandono de acuerdos formales o informales sobre flexibilización funcional y externa de la mano de obra. Empresas como Colmotores aprovecharon la crisis económica de la década de los ochenta para adelantar una estrategia drástica de costos con fines económicos y políticos orientada a cambiar en términos cuantitativos y cualitativos la mano de obra, con miras a transformar la base social en que se apoyaba la organización sindical y socavar así su poder de negociación. En este período fueron comunes los despidos antes de los diez años, las solicitudes de despidos colectivos ante el Ministerio de Trabajo $^{6}$, los planes de pre-jubilación, las llamadas a negociar retiros "voluntarios" y la suspensión de contrataciones a termino indefinido. Políticas posteriormente imitadas por la dirección empresarial de Sofasa que veía como condición para la introducción de la gestión de la calidad total-jat la transformación de las relaciones antagónicas. Para lo cual adelantó una política agresiva de reducción de costos laborales orientada, igualmente, a cambiar la base social de la que se nutria este tipo de relaciones. Líderes sindicales con una tradición de lucha política, acompañados de un grupo importante de trabajadores con prácticas acentuadas de movilización y de relaciones de choque con los jefes inmediatos. La dirección empresarial no escatimó esfuerzos para despedir y/o negociar la salida de trabajadores considerados indeseables, dentro de los cuales se encontraba la cúpula sindical (López, 1997). Más aún, para algunos de los entrevistados, la dirección empresarial no dudó en sacrificar la productividad con tal de cambiar la base social que era cercana a la organización sindical.

En este tipo de empresas, las décadas del ochenta y noventa se caracterizaron por lo que algunos llamaron gráficamente la "llegada de sangre nueva" a los ámbitos empresariales. Ingresan trabajadores jóvenes, con una mayor escolaridad y sin experiencia sindical, que mostraron disposición a disciplinarse, es decir, a asumir las nuevas exigencias técnicas y sociales del orden empresarial sin cuestionamiento ni crítica. La llegada de

Defensoría del Pueblo, Ministerio Público, Comunicado a la opinión pública, Medellín. La solicitud de autorización de desvinculación masiva de trabajadores se ha vuelto común en Colombia, como lo señala la Defensoría del Pueblo, "un grueso número de factorías, en procesos de reconversión tales como: Coltabaco y Polímeros de Colombia, y ya se autorizaron despidos en Avianca, Sofasa y Simesa... detrás de la autorización de despidos colectivos se conjugan derechos como la disminución progresiva del número de afiliados al sindicato, lo que genera desaparición del ente sindical y una vulneración del Derecho de los trabajadores". 
este contingente y la salida de un importante grupo de trabajadores antiguos sumada a la "guerra sucia", restaron recursos de poder a las organizaciones sindicales, que quedaron sin mayor respaldo social para negociar u oponerse al nuevo orden (las organizaciones sindicales de dos de las empresas estudiadas no fueron ajenas al asesinato de líderes sindicales).

Es así como la introducción de la gestión de la calidad-jat en Colombia, está enmarcada por un lado, por persistentes crisis económicas y, por otro lado, por una política de costos, que se adelanta con mayor rigor previamente a la introducción de dicha de estrategia de gestión, sin que pierda continuidad a través de los años. "Política de costos" que entra en franca contradicción con la racionalidad material que la sustenta, orientada a consolidar relaciones de confianza entre capital y trabajo y disposición incondicional de los trabajadores respecto al proyecto empresarial.

\section{- Remover instituciones: en pos de la flexibilidad funcional}

La pretensión de la estrategia de la calidad total-jat de hacer de las empresas unidades magras y flexibles, tocó puntos centrales de la negociación colectiva en aquellas empresas con mayor capacidad de negociación sindical: a) flexibilidad funcional de la mano de obra o movilidad interna de los puestos de trabajo y b) flexibilidad externa, traducida en externalización de funciones o ampliación de la contratación de trabajadores temporales.

Hay que destacar que sólo en aquellas empresas con una tradición de relaciones antagónicas, las organizaciones sindicales lograron espacios de negociación que limitaban el tipo de contratación y la movilidad funcional (ver Cuadro 1). La abolición de este último punto era imprescindible en el marco de la estrategia de la gestión de la calidad que reclamaba un trabajador polifuncional, orientado hacia el mejoramiento continuo y al autocontrol. Prácticas, hasta ese momento, desestimadas por la dirección empresarial e institucionalizadas, en algunos casos, a través de las convenciones colectivas. En empresas como Sofasa, cuya convención colectiva rezaba la no-movilidad interna de los trabajadores, esta política contribuyó a agudizar el conflicto que finalmente desencadenó en una prolongada huelga y en la exclusión definitiva del sindicato. Bajo el influjo de grupos externos políticos, el sindicato continuo con una táctica radical de lucha, que llevó a una escalada del conflicto en el interior de la empresa; sin percatarse de la pérdida de recursos de poder, pues ya no contaba con apoyo suficiente de las bases, sumado a que socialmente la empresa asociaba los bajísimos rendimientos económicos exclusivamente al conflicto laboral existente. Ello llevó a que el gobierno aprobara el despido de 169 trabajadores de los 600 solicitados por la dirección empresarial, situación que restó aún más poder de negociación a la organización; a tal punto que la empresa presenta un pacto colectivo al cual se acoge la gran mayoría de trabajadores, jóvenes recién enganchados, sin referentes colectivos de lucha.

Por su parte, el sindicato de cemento procuró abandonar su tradicional 


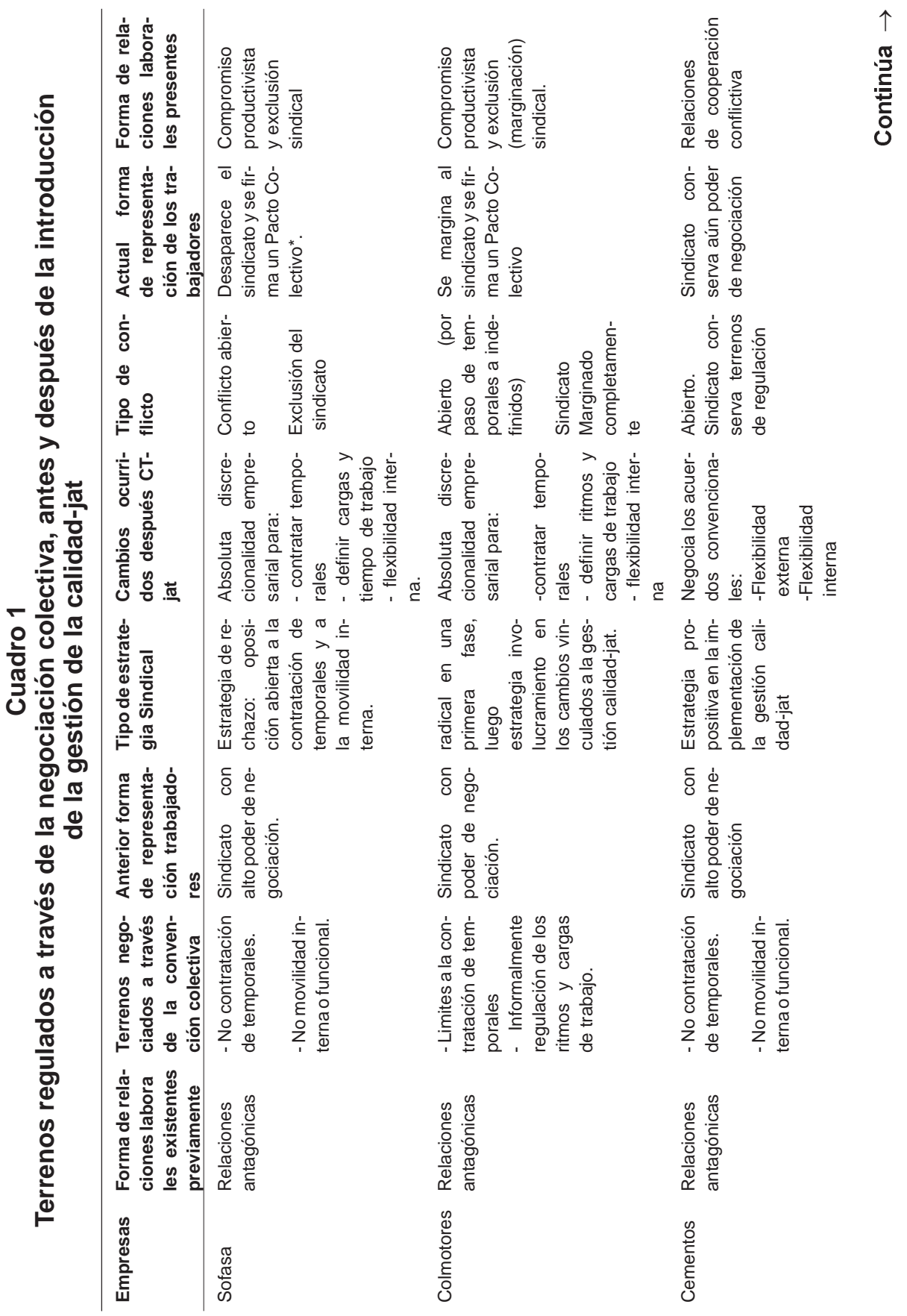




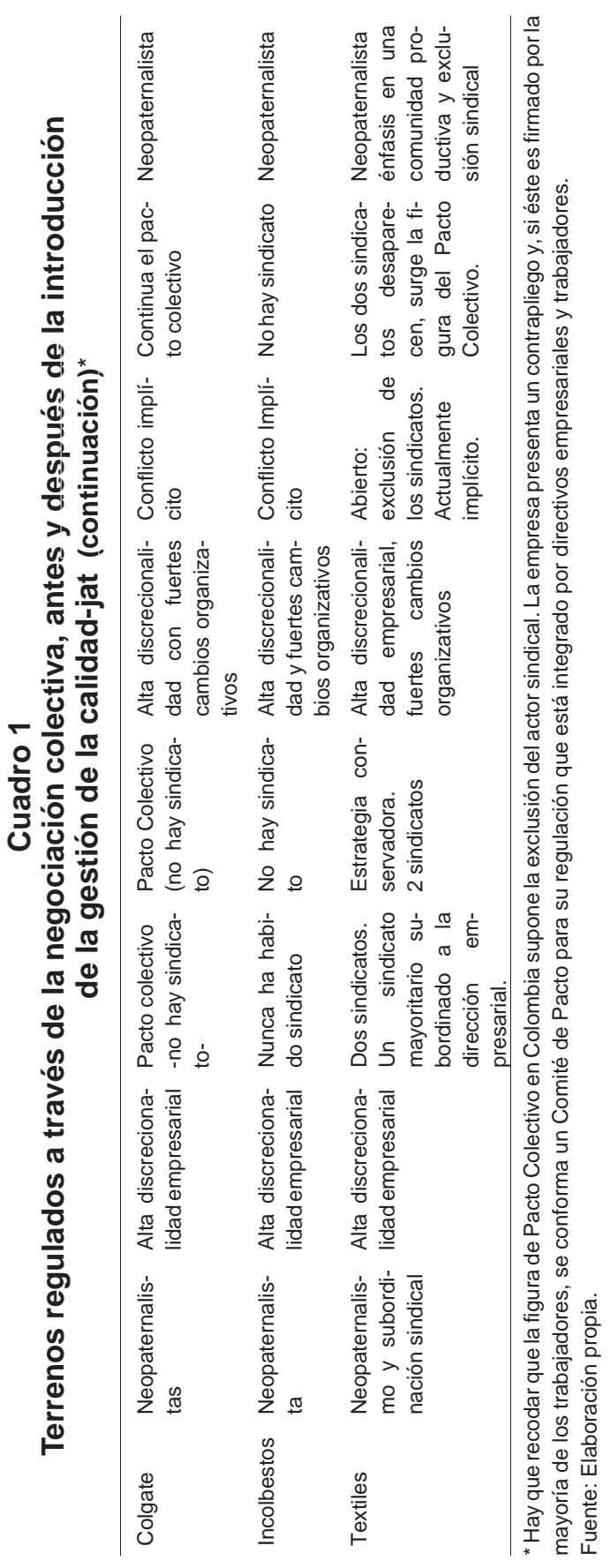


estrategia de choque y negociar los cambios. Y el de Colmotores observó cómo a pesar de transformar su estrategia de choque y procurar involucrarse en los cambios, terminó perdiendo el poder informal de regulación de los tiempos y ritmos de trabajo.

Bajo esta forma de relación se observó una extrema radicalidad de la dirección de las empresas para avanzar en la implementación de la estrategia de la gestión de la calidad-jat. Bien sea por presiones de un entorno menos predecible y controlable, o por su tradicional hostilidad hacia las organizaciones sindicales, las empresas aprovechan algunas coyunturas para desplegar su poder de manera ilimitada y debilitar las instituciones que consideran insostenibles en el tiempo y, a la vez, debilitar o excluir a las organizaciones sindicales. Ni siquiera donde la organización sindical asumió una estrategia de involucramiento éste logró salir fortalecido. Es el caso del sindicato de Colmotores, que después de participar activamente en la implementación de la gestión de la calidad-jat, la empresa ve la oportunidad de debilitarlo y lo hace, hasta lograr su completa marginación, sustitu- yendo la Negociación Colectiva por la figura del Pacto Colectivo ${ }^{7}$.

\section{- Remover instituciones: la estabili- dad laboral}

Hasta inicios de los años ochenta, la estabilidad era una institución valorada y negociada por las organizaciones sindicales de las empresas estudiadas. EI Cuadro 2 señala cómo la estrategia de costos sí desencadenó en conflictos abiertos entre empresa-trabajadores, más que las políticas organizativas en sí mismas (a excepción del caso de Sofasa). Esta estrategia atentaba contra la médula de la organización, es decir, excluía a sus afiliados y no generaba condiciones para el ejercicio libre del derecho de sindicalización. En aquellas empresas bajo relaciones antagónicas la base social fue prácticamente cambiada, alrededor del $70 \%$ de la misma. Sólo donde el sindicato contaba con amplio respaldo de las bases y asumió una estrategia propositiva y concentró sus recursos de poder en la participación y movilización potencial de los trabajadores, logró restar efectividad a esta estrategia empresarial (Cementos).

Desde finales de la década del ochenta Colmotores había suspendido los contratos a término indefinido, acrecentándose cada año el porcentaje de trabajadores temporales. Al finalizar la década del noventa el sindicato logra el apoyo de todos los trabajadores, incluyendo los temporales, y va a huelga motivado por el cambio de tipo de contrato. La empresa despliega todos sus recursos de poder, incluso va a las casas de los trabajadores para que desistan de la huelga, y finalmente ésta es declarada ilegal y casi a la totalidad de trabajadores temporales les es suspendido el contrato y la empresa aprovechó para continuar con su política de llamados a negociar el retiro anticipado a la jubilación. El sindicato quedó totalmente debilitado, marginado sin mayor capacidad de acción a tal punto que en la actualidad sólo pertenecen a él menos del 15\% de los trabajadores de planta, pues la parte administrativa prácticamente no hizo nunca parte del mismo. 


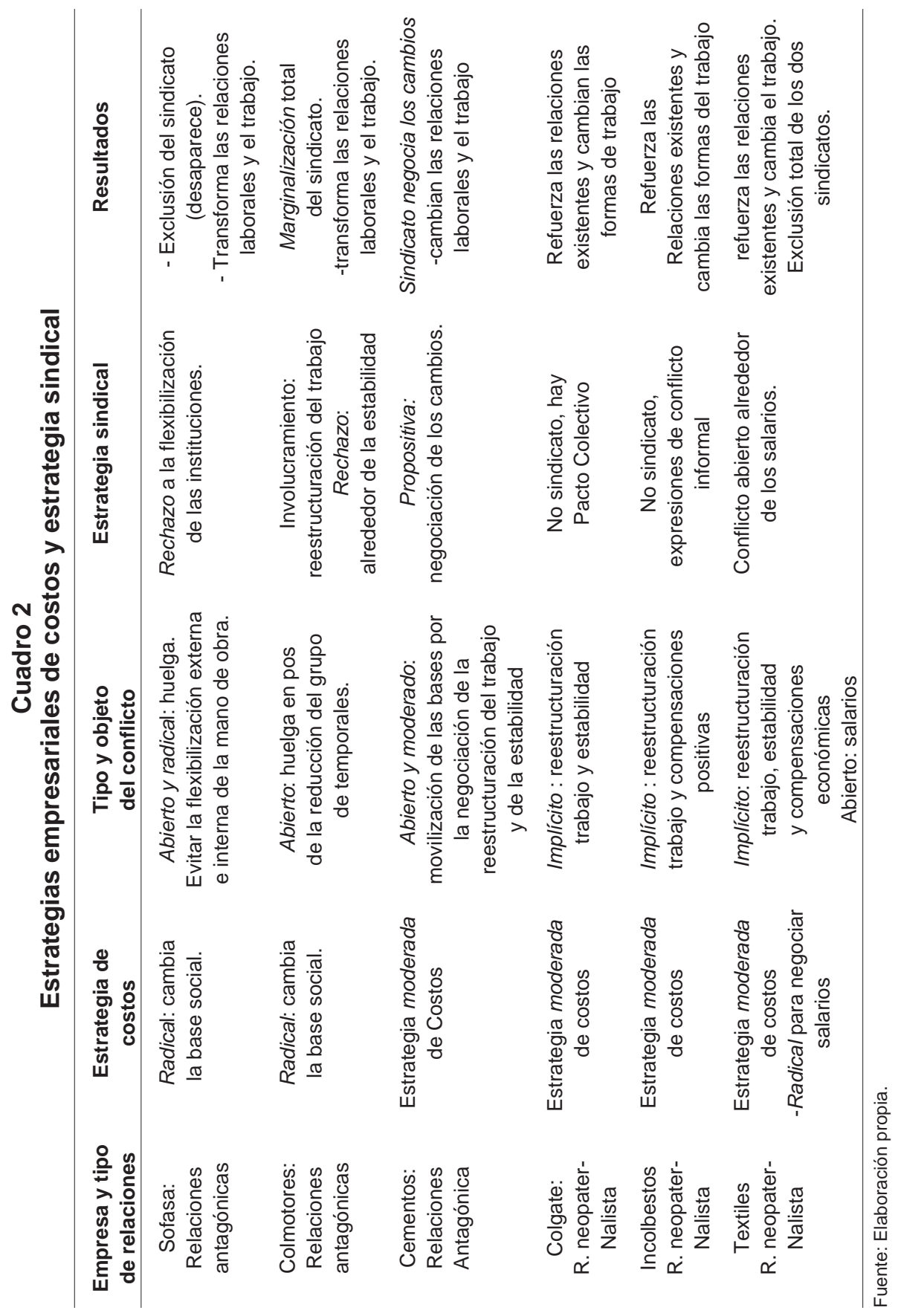


Este mismo cuadro resume el sentido de la política de costos adelantada por las diversas empresas del estudio y las estrategias sindicales respectivas. Una estrategia de rechazo total a la flexibilización de las instituciones reguladoras de la contratación y de las condiciones de empleo (flexibilización externa e interna) desencadenó en la desaparición del sindicato y en la configuración de relaciones basadas en un compromiso productivista fundamentadas en la exclusión sindical (Sofasa). Una estrategia consenadora que después giró hacia el involucramiento pero sin un sólido respaldo de los trabajadores -en el marco de una radical política de costos- marginó la organización sindical (Colmotores); y se construyen espacios de compromiso productivista que excluyen al sindicato. Una estrategia propositiva, apoyada en la motivación y movilización potencial de los trabajadores no sólo garantizó la existencia de la organización sino que le permitió negociar parte de los cambios y resultados de la reestructuración, lo cual dio paso a la construcción de relaciones de cooperación conflictiva.

En la década del noventa, en las empresas estudiadas, especialmente en aquellas con un pasado de negociación sindical, la práctica de contratación de temporales se institucionaliza sin contar con la mediación de los sindicatos. La tasa de temporalidad llega a alcanzar hasta el $60 \%$ de los trabajadores, sumado a que muchas funciones consideradas en el pasado como centrales se externalizan. Es así como los ingenieros, ethos de la racionalidad en tiempos tayloristas, ingresan a las empresas a través cooperativas ${ }^{8}$.

Este mismo cuadro muestra que en tres de las seis empresas estudiadas se transformaron las relaciones laborales. Estos casos correspondieron a las empresas con relaciones antagónicas. Dos de esas empresas se transforman de manera tan sustancial que marginaron o excluyeron al actor sindical. El peso de la gestión de la calidad-jat en los cambios fue directo e indirecto. Indirecto en el sentido que su implementación requirió el desplazamiento previo de las relaciones laborales existentes y directo porque reforzó los cambios y el sentido de los mismos.

En las empresas estudiadas se evidencia la ideología empresarial poco favorable a la presencia de los sindicatos en los ámbitos empresariales. Si bien, es difícil pensar que había objetivos claros (exclusión definitiva de los sindicatos), lo que sí es evidente es que las empresas hacen uso del margen de variación de los recursos tácticos o de poder y aprovechan las coyunturas para restar poder a las organizaciones sindicales y, si es el caso, excluirlas de la contienda empresa-

8 La vinculación laboral a través de cooperativas se impone cada vez más en especial en entidades del Estado y sector agroindustrial. Su característica principal es que el trabajador no establece una relación laboral con la cooperativa y en esta medida carece de derechos tales como: vacaciones, primas, seguridad social, pensiones, entre otras. Si desea gozar de estos derechos deben ser cubiertos en su totalidad por el trabajador. 
rial. Como señalan Crozier y Friedeberg (1990), en lugar de ser racional con arreglo a ciertos objetivos lo es, por una parte, en relación con las oportunidades y a través de éstas con el contexto que las defina y, por otra, en relación con el comportamiento de los otros actores, con el partido que toman y con el juego que se establece entre ellos.

Según la dirección empresarial había que "generar condiciones" para la implementación de una gestión de la calidad total-jat, y no se escatimaron medios para ello. La "exclusión del contrario" o su total marginación, propio de las tácticas a nivel de lo político, hizo parte de la acción empresarial. Sólo cuando la empresa recobró el control sobre la fuerza de trabajo realizó una drástica reestructuración productiva apoyada en los grupos de trabajo, acercándose a una reestructuración sistémica y de procesos.

Como señalan Kochan \& MacKersie para el caso estadounidense, de la misma manera que las ideas de los empresarios actúan como un filtro mental que selecciona las opciones estratégicas, la consideración de involucrase en la estrategia de la gestión de la calidad para mediar en los centros de trabajo supone un cambio fundamental en lo que respecta a la escala de valores y orientación estratégica de los líderes sindicales (1993:245). Por todo lo anterior, la decisión de los sindicatos de intervenir en el proceso de toma de decisiones de la empresa implica una ruptura con estas concepciones tan firmes sobre lo que era una estrategia adecuada. Pero también supone una estrategia diferente de la dirección empresarial, que contemple como válido, e incluso estratégico, la vinculación de los sindicatos a los procesos de reestructuración empresarial.

La reticencia empresarial a negociar los cambios puede deberse al marco ideológico en el que la empresa y el sindicato se apoyan para formular estrategias; a que los sindicatos no poseen experiencia ni poder de negociación de los cambios en los procesos de trabajo -su experiencia ha sido meramente salarial y de estabilidad-; a que la diferenciación entre los trabajadores los lleva a la ambigüedad en el respaldo a los cambios; a que las reformas en el sistema de autoridad pueden gustar a muchos trabajadores que saludan lo novedoso de los espacios de "participación", más si dentro de su arsenal de estrategias se incluyen programas de integración de las familias de los trabajadores a la empresa.

No sobra destacar que la estrategia empresarial orientada a minar la capacidad de negociación de las organizaciones fue más eficaz aún por la debilidad misma de las organizaciones sindicales cuyo poder, a su vez, fue socabado por factores externos e internos. Externos como la "guerra sucia" y la pérdida de legitimidad de los discursos basados en relaciones antagónicas, a los cuales se suman las políticas de desregulación del mercado laboral y el creciente desempleo. Todos estos elementos le restan poder social de negociación a los trabajadores en su conjunto. Factores internos fueron las políticas de costos y la "artrosis institucional" de las organizaciones sindicales, esto es, la separación de las estructuras organizativas de sus miembros. Mejor dicho: la organización está desvinculada de la participación y capacidad de movilización de los trabajadores lo cual 
mina desde el interior su poder real (Offe, 1990). En un ámbito de hostilidad sindical, entonces, las estrategias sindicales conservadoras o radicales, terminan por causar el mismo efecto: debilitación o exclusión de las organizaciones.

Para finalizar sólo resta señalar que, si bien las estrategias de las organizaciones sindicales juegan un papel determinante en la repercusión que pueda tener la gestión de la calidad-jat en la transformación de las relaciones laborales al filtrar las estrategias empresariales, éstas últimas no alcanzan suficiente eficacia mientras los sindicatos no tengan amplios recursos de poder que les permitan materializarlas. En este sentido, y debido a la asimetría de los recursos de poder entre empresa-trabajadores, las estrategias de la dirección empresarial tiene un mayor poder de transformación de las relaciones laborales.

\section{- Se refuerzan y consolidan las rela- ciones neopaternalistas}

Mientras en las empresas en donde se habían construido relaciones "neopaternalistas" como en Incolbestos o Textiles, caracterizadas por la presencia de profesionales encargados, no sólo de gestionar técnicamente las empresas sino de materializar una ideología de gestión que busca el predominio de relaciones directas con los trabajadores y cierta "responsabilidad" para con ellos, la introducción de la gestión de la calidad-jat no estuvo antecedida por una fuerte estrategia de costos.

Como no había negociaciones previas entre empresa y trabajadores sobre las condiciones de trabajo y de empleo, la dirección empresarial contó con una alta discrecionalidad para adelantar los cambios organizativos sin que esto desencadenara en conflictos abiertos; excepto en el caso de Textiles donde hubo protestas informales por parte de un grupo minoritario de obreros que mostraron su disconformidad por la intensificación del trabajo y por la segmentación de los trabajadores (entre los que pertenecían a los grupos de trabajo y los que no). No obstante estas protestas puntuales, los sindicatos, uno más que otro, no asumieron estos temas como parte de su agenda. Sin embargo, esta estrategia conservadora tampoco los libró de su exclusión, pues cuando la dirección empresarial vio la oportunidad de excluirlos no escatimó esfuerzos para hacerlo; y en respuesta a las nuevas circunstancias propugnó por consolidar las relaciones neopatemalistas existentes.

Las empresas suelen tratar los cambios como algo de su exclusiva propiedad que no requiere ni de respaldo ni de acuerdo con los sindicatos, a lo más que llegan es a informar sobre los nuevos proyectos organizativos, pero no acostumbran permitir la participación de la organización. Es significativo que en aquellas empresas en las que se adelanta con relativo éxito la gestión de la calidad, las relaciones laborales suelen regularse sin sindicato, a través de Pactos Colectivos o de sindicatos con una estrategia conservadora que centran la negociación en aspectos económicos, sin tocar la organización del trabajo. 


\section{- Nuevas Formas de Relaciones La- borales}

Como resultado de la estrategia de la calidad total-jat se fortalecen relaciones neopatemalistas en aquellos ámbitos cuya existencia ya estaba consolidada (Incolbestos, Colgate y Textiles). Estas relaciones se distancian de las relaciones patemalistas encontradas en algunas empresas colombianas hasta bien entrado el siglo pasado, porque históricamente los actores empresariales, las instituciones sociales y políticas y el mercado se han transformado.

Primero, el empresario ha sido sustituido por una tecnocracia que aunque se muestre dispuesta a continuar con relaciones personalizadas y directas con los trabajadores debe subordinarlas a una estrategia de costos o vincularlas a un objetivo productivo y/o político. La responsabilidad empresarial está asociada a una racionalidad formal más que a una material y a la consideración de la fuerza de trabajo como un recurso al que hay que motivar para potenciar productivamente.

Segundo, la gerencia abandona el interés de reclutar y retener la mano de obra con el propósito de disciplinarla productivamente porque hay un mercado desbordado por la oferta, escolarizado y una mano de obra dispuesta a disciplinarse y subordinarse a la autoridad empresarial. Ahora se necesita retener sólo a una parte de los trabajadores para implicarlos y potenciarlos, así se construye una comunidad productiva caracterizada por su eficiencia y capacidad de generar resultados, en el marco de relaciones sociales previsibles y controlables.
Tercero, la intervención de la dirección empresarial en la esfera del "no trabajo" no pretende ser totalizadora pues, a diferencia de las relaciones paternalistas, carece del propósito de construir un "hombre nuevo" (Sierra, 1990). Si bien la empresa desiste de la pretensión de ser una organización totalizante, no abandona la preocupación de controlar parte de la esfera privada de los trabajadores como condición para garantizar su compromiso con la empresa. Ahora procura cuidar de manera limitada y selectiva a ese impredecible y potencialmente no controlable recurso que es la fuerza de trabajo.

Cuarto, en lo que sí se parecen las estrategias neopaternalistas y paternalistas es en el hecho de adelantar una serie de políticas de integración y bienestar orientadas a conjurar la autoorganización de los trabajadores; dichas políticas son presentadas como una gratuita discrecionalidad de la dirección empresarial. Aún se considera a los trabajadores como menores de edad, incapaces de construir su propia cultura y definir sus intereses. Contrasta la voluntad activa de la dirección empresarial con la pasividad impuesta al trabajador. En este sentido "el obrero deviene predicado, objeto", como diría Sierra (1990).

Las políticas de bienestar e integración, sumadas a radicales políticas de despidos por la simple sospecha de autoorganización de los trabajadores, logran, bajo esta forma de relaciones laborales, desestimar la autoorganización de los trabajadores y/o consolidar sindicatos subordinados a las políticas de la dirección empresarial. 
Quinto, sumado a lo anterior, es necesario destacar que el operario de hoy es un trabajador histórica y socialmente construido de modo diferente. Se implicará en el trabajo y participará activamente en él -si la empresa brinda espacios para ello- pero su compromiso y disposición a desplegar su fuerza de trabajo de manera ilimitada estarán determinados a la existencia de relaciones de reciprocidad. El trabajador que ingresa hoy a la industria no proviene del campo, tiene mayor escolaridad y se ha socializado en el mundo urbano y laboral. Tiene una trayectoria laboral en el sector de la construcción, los servicios o la industria, su experiencia en el mundo del trabajo le permite reconocerse como un individuo con derechos históricamente construidos y socialmente reconocidos, con independencia de si los usufructúa o no.

Así como se reafirman las relaciones neopaternalistas, también se abandonan las relaciones antagónicas y se da paso a "compromiso productivista basado en la exclusión sindical". Aunque en algunos aspectos este tipo de relaciones se acerca a lo que hemos denominado relaciones neopaternalistas, pensamos que no deberían ser consideradas como tales por el pasado de lucha-tregua entre capital y trabajo, por la ausencia de un historial de relaciones directas entre la dirección y los trabajadores (a veces de tipo carismático), y porque gran parte de los trabajadores actuales no cuentan con estabilidad laboral.

Esta nueva forma de relación, por un lado, son relaciones colectivas ya que sobreviven estructuras, normas y costumbres que cubrian a todos los trabajadores de manera colectiva las cuales son recogidas en el Pacto Colectivo y, en parte, protege a los trabajadores de una total arbitrariedad empresarial; por otro lado, son relaciones individuales en la medida en que el rendimiento y su retribución, al igual que los conflictos cotidianos y solicitudes que demanda el operario en términos de permisos o préstamos no pasan por la mediación de un sindicato sino que se tramitan o resuelven de manera directa con el jefe.

Este tipo de relaciones excluye la posibilidad de una "negociación" en un sentido amplio pues no parte del reconocimiento de intereses diferentes entre capital y trabajo. Los trabajadores no tenían mediadores que los representaran -tanto sus jefes como sus compañeros de trabajo hacian parte del Comité del Pacto-. La empresa gana alta discrecionalidad para la regulación de salarios y prestaciones sociales y del mercado interno de trabajo. Sin embargo, para legitimar el Pacto Colectivo debe esforzarse por responder a las expectativas económicas de los trabajadores, de tal manera que pareciera innecesaria la presencia de una organización colectiva que los represente. La empresa busca crear una identidad positiva en torno a la cual unificar a los trabajadores y hacerlos funcionales a sus fines. El discurso de "la gran familia" pretende comprometer a los trabajadores en el proyecto de una comunidad productiva empresarial, pues la lucha no es contra las condiciones de trabajo existentes sino en contra de las empresas competidoras, por ello todos deben asumir una cuota de sacrificio. El editorial del órgano informativo de Sofasa señala:

"El pacto colectivo significa una base sólida para el desarrollo de unas bue- 
nas relaciones laborales. Su filosofía implica una relación directa y armónica entre los trabajadores y la administración, en procura del fortalecimiento de la empresa. Para ello precisamos el compromiso de todos quienes hacemos parte de esa gran familia, pues la dinámica del esquema actual de los negocios empresariales nos obliga a actuar de una manera integrada y coherente para afrontar con éxito los retos de un mercado difícil y altamente competitivo" (Editorial, Notisofasa, No. 27, Octubre/94, Medellín).

No obstante el optimismo, la dirección empresarial reconoce la dificultad de poner en potencia la fuerza de trabajo y comprometerla hasta el punto que se consoliden relaciones de lealtad para con la empresa, en especial porque para alcanzar sus fines las organizaciones desplegaron sus recursos de poder de manera ilimitada, sin importar los medios y las consecuencias para los trabajadores -individual y colectivamente-. Aunque los nuevos trabajadores no lo vivieron, este historial de lucha abierta entre capital y sindicato ha dejado su huella.

A corto plazo en las empresas estudiadas no existe capacidad para construir una acción colectiva. Hay un ambiente de aceptación los Pactos Colectivos como algo favorable, que responde a las necesidades de los trabajadores en términos económicos. Sin embargo, hay incertidumbre respecto al mercado y la responsabilidad que la empresa estaría dispuesta a asumir frente a los trabajadores, en especial cuando la apertura económica acrecienta la incertidumbre empresarial. Pero, el hecho de que la gran mayoría de los obreros estén vinculados como temporales resta eficacia a los reclamos de lealtad.

Ante estas circunstancias los trabajadores que han tenido reservas con el Pacto Colectivo, con la intensificación del trabajo y con los impedimentos para auto-organizarse, tampoco quieren asumir riesgos y aunque no tienen confianza en la empresa tampoco están dispuestos a confrontarla. En el momento actual la posibilidad de enfrentamiento al orden empresarial es marginal, el empresario no se presenta como un contrincante al cual hay que enfrentar para hacer valer derechos que responden a intereses particulares que, a veces, se distancian de los intereses de la empresa.

La ausencia de representatividad sindical no garantiza, como quisiera la dirección empresarial, la eliminación del conflicto; como la debilidad individual y colectiva de los trabajadores no es la base de la paz laboral no sería extraño que en un futuro no muy lejano los trabajadores asumieran la búsqueda de espacios de negociación o concertación que involucraran también sus intereses particulares. Los conflictos están latentes y los canales de expresión son incipientes. Aunque la identidad colectiva de los trabajadores es muy endeble y no hay una correlación de fuerzas que les permita articularse a un proyecto colectivo, la lucha por poner en acto y en potencia la fuerza de trabajo no desaparece, los trabajadores asumen estrategias informales para evitar los excesos de la empresa en el uso de la fuerza de trabajo. Este aspecto se abordará con mayor detenimiento a continuación. 


\subsection{Transformaciones en el trabajo \\ - ¿Cambian los contenidos del tra- bajo?}

Teórica y empíricamente esta estrategia se fundamenta no sólo en la existencia de relaciones de confianza entre empresa y trabajadores, sino en instituciones flexibles para adecuar la producción a la demanda, uno de sus objetivos. Hay una cuestión de fondo que contribuye a transformar las formas de trabajo existente: la demanda de flexibilización interna de la mano de obra.

En teoría la gestión de la calidad total-jat se distancia de la propuesta taylorista basada, a su vez, en una división estricta entre quién planea y ejecuta, en puestos de trabajo muy demarcados apoyados en la especialización del trabajo, con relaciones jerarquizadas que desdeñan la participación, la autonomía y el autocontrol del operario en el trabajo, además de la construcción de relaciones de pertenencia del trabajador para con la empresa como base de su implicación en el trabajo.

La propuesta de una reestructuración sistémica y de procesos gira alrededor de los grupos de trabajo, llamados también células, unidades o equipos de trabajo o simplemente grupos autónomos, y está apoyada por cambios significativos en la organización del trabajo. En teoría demanda la interrelación de cuatro elementos: calificación, participación, autonomía y autocontrol ${ }^{9}$.
Las empresas estudiadas suelen ser selectivas en la introducción de cambios organizativos en áreas o procesos productivos; como los cambios no afectan a todo el contingente de trabajadores sino a un grupo, éstos procedimientos terminan por reforzar la diferenciación y fragmentación de los trabajadores. En las empresas visitadas en la presente investigación no se observan cambios muy optimistas ligados a la cristalización de grupos autónomos como lo recoge el Cuadro 3.

Apoyándonos en los elementos conceptuales expuestos por Marín (1995), podemos concluir que en las empresas estudiadas la rotación de tareas es baja y, cuando ocurre, suele ser parcial, se circunscribe a una serie de tareas articuladas a una actividad específica; en algunos casos los intentos de rotación han sido abandonados por los costos de aprendizaje. Como no hubo mayor oposición de los trabajadores se ampliaron las tareas en un marco de especialización. En la gran mayoría de las empresas los cambios, que cubren a un amplio número de trabajadores, no pasan de ser lo que, en términos de Marín, se llamaría una ampliación horizontal de tareas y una extensión de tareas. Aunque se observa un cierto avance en el control del trabajo y la extensión de responsabilidades -calidad y mantenimiento-, la gran mayoría de trabajadores no dispone de autonomía para diseñar, planear y regular internamente 


\section{Cuadro 3}

\section{Cambios en la organización del trabajo, por empresas}

\begin{tabular}{lccccc}
\hline Cambios organizativos & A & B & C & D & E \\
\hline Rotación de tareas & Baja & Baja & Baja & baja & Baja \\
Ampliación horizontal & Media & Media & Media & alta & Baja \\
Extensión de tareas & Media & Media & media & alta & media \\
Ampliación vertical & Media & media & Baja & media & media \\
Enriquecimiento de tareas & I.p.g & I.p.g. & I.p.g. & I.p.g. & I.p.g. \\
Grupos autónomos trabajo & Bajo & bajo & - & bajo & Bajo \\
\hline
\end{tabular}

Fuente: entrevistas y visita a las empresas, 1998.

Escala: baja, media, alta y I.p.g = limitado a pequeños grupos.

A: Colmotores, B: Incolbestos, C: Cementos, D: Textiles y E: Colgate.

su trabajo. Pueden llegar a determinar quién hace las cosas pero no cómo se hacen. En general, la especialización y rutinización caracterizan aún las labores del mayor contingente, independientemente de que a las labores habituales se le sumen tareas operativas y de control de la calidad e, incluso, de limpieza de las máquinas y aseo de los puestos de trabajo.

De manera selectiva para algunos grupos, en especial los ligados a actividades que demandan calificaciones técnicas, los cambios han contribuido a ampliar sus tareas tanto horizontal como verticalmente, aunque, casi siempre, en un marco de especialización y baja autonomía en el trabajo. Hay un cierto enriquecimiento del trabajo de estos grupos en la medida que han asumido nuevas labores sociales, que requieren mayor capacidad de comunicación e intercambio entre las diferentes áreas productivas y administrativas, y que ganaron espacios limitados de regulación de su trabajo.

En empresas como Textiles y Colmotores, por ejemplo, las unidades o celdas de trabajo permitieron cierta autonomía en cuanto a distribución de tareas, aspectos disciplinarios e, incluso, diseño de algunas actividades. En un principio Colmotores intentó construir una organización más próxima a una ampliación vertical de tareas pero retrocedió hasta acercarse más bien a una extensión de tareas. Mientras por un tiempo Textiles avanzó hacia la configuración de lo que podría llamarse teóricamente, si hubiese continuado en esa línea, grupos autónomos de trabajo.

comprometidos con el proyecto empresarial. Construir una "comunidad productiva" supone la consolidación de relaciones de confianza entre empresa y trabajadores, además de cierto sentido de pertenencia del trabajador con la empresa, elementos que se distancian de la visión taylorista que considera que el trabajador se orienta fundamentalmente por motivaciones de orden económico. 
No obstante, los casos estudiados muestran intentos positivos de reestructuración del trabajo con logros importantes en cuanto a elevación de la productividad asociada a intensificación del trabajo; se observa, además, una progresiva extensión de tareas y de responsabilidades que demandan del trabajador nuevas cualidades y conductas como competencias lógicas, matemáticas y comunicativas. Estos cambios han desplazado, paulatinamente, la figura del supenisor-capataz y han limitado la arbitrariedad en el trabajo. En empresas como Colmotores esta figura, valuarte del taylorismo, desaparece de la estructura jerárquica y es remplazada por los jefes de grupo. Es decir, operarios que ejercen una labor de intermediación entre los operarios y los ingenieros, sin que reciban mayor retribución dineraria por las nuevas labores asumidas.

Las nuevas formas organizativas, de manera selectiva, amplían las calificaciones y responsabilidad de los operarios en el trabajo; suelen distensionar las relaciones de autoridad mediante el establecimiento de comunicaciones más espontáneas y directas afectando así las distancias sociales entre jefes y operarios. Sin embargo, los trabajadores no fueron considerados en el momento de reestructurar las plantas, los ingenieros hicieron un uso selectivo de la experiencia de los trabajadores pero no los involucraron como actores capaces de definir los contenidos de los trabajos, sus tiempos y descansos. Una vez reestructurada la planta los trabajadores no obtuvieron espacios para negociar ritmos de trabajo, número de máquinas a operar o revalorización de las calificaciones. Más aún, en algunas lugares desaparecieron los tiem- pos de descansos. Al igual que las experiencias adelantadas en la década de los ochenta, los operarios se enrolan en los grupos de trabajo y participan en ellos como integrantes de procesos de cooperación con intereses en un trabajo eficiente y reconocido, no como asalariados con intereses en remuneraciones y estabilidad. Por tanto, no se incluye el problema de la repartición de los beneficios; se desestiman consideraciones de orden económico como parte de la motivación, el trabajador debe atenerse a la simple satisfacción del trabajo.

Estas nuevas formas organizativas, que abren espacios de participación restringida, traen consigo cambios significativos en las formas de organización de procesos de trabajo y cuestionan algunos principios de legitimación de la autoridad; sin embargo, la estructura misma de autoridad, en esencia, no se transforma. En la medida en que los obreros no logran apropiarse de la dirección de su trabajo, el rompimiento de las jerarquías es temporal, se reduce al momento de la "comunicación" de los contenidos técnicos orientada a la mejora de los procesos de trabajo. La decisión final sobre la reestructuración del trabajo continúa en manos de la dirección de la empresa, es decir, no se ha roto significativamente con la tradicional división entre quienes planean y quienes ejecutan el trabajo ${ }^{10}$.

No obstante lo limitado de sus cambios, para el caso colombiano no se puede afirmar, como señalan Kochan et al. (1997), que los nuevos sistemas son una extensión del taylorismo, por dos razones. Primero, si bien las calificaciones, la autonomía y la participación no se amplían de manera considerable, sólo de 
manera parcial para un grupo reducido, sí cambian los principios por los cuales se rige el trabajo, se intenta legitimar la autoridad y se convoca a la cooperación. Segundo, en este sentido, las relaciones sociales tanto entre jefes como entre los mismos trabajadores se plantean desde condiciones materiales diferentes y discursos de gestión que se distancian del taylorismo y por lo tanto procuran ser legitimados desde otras dimensiones ${ }^{11}$.

\section{- Apoyados en la diferenciación de los trabajadores se cuestionan los roles y se redefinen los códigos la- borales}

Como hemos señalado, primero, la estrategia de la gestión de la calidad se implementa en contextos, en unos más que en otros, en los que priman las relaciones de baja confianza entre empresa y trabajadores. Es el caso de las empresas con un pasado de relaciones antagónicas (Sofasa, Colmotores y Cementos) y en menor medida en empresas donde se reafirman las relaciones neopatemalistas (Incolbesto y "Textiles"). Segundo, en empresas donde la base social es prácticamente cambiada (Sofasa) o donde la contratación de temporales se amplia significativa (Colmotores, Colgate y Textiles) o muy moderadamente (Incolbestos y Cementos). Ambas situaciones acentúan la diferenciación entre trabajadores antiguos y jóvenes o temporales.

Estos dos elementos, relaciones de baja confianza y mayor contraste entre trabajadores jóvenes o temporales y antiguos, permiten comprender y explicar cómo las empresas materializan la gestión de la calidad-jat en los centros de trabajo, incluso, en contraposición silenciosa de los trabajadores. ¿Qué significa el trabajo en equipo en contextos de baja confianza entre empresa y trabajadores, en los que la salida de amplios contingentes ha supuesto la pérdida de la memoria colectiva y contrasta con el ingreso de jóvenes trabajadores, cuyas identidades apenas están en construcción y que des-

10 Esto no parece ser tan diferente, ni siquiera en el Japón, según Weiss (1997: 202): “Existen, incluso, diferencias en la acepción semántica en Japón y en Occidente, en relación a lo que se entiende por participación, o trabajo en grupo. Por "participación", por ejemplo, se entiende en el Japón la posibilidad de ser incluido en un proceso de consulta. Los directivos informan sobre las decisiones, sin que haya una vinculación activa en la toma de decisiones en los niveles bajos de la jerarquía empresarial. La información como consulta no implica que haya una negociación sobre las decisiones. Una serie de aspectos, como las condiciones del trabajo, la seguridad laboral, o aspectos técnicos de organización del trabajo, son objeto de información que se designa como consulta, pero que no implica una 'participación' en la toma de decisiones ni la posibilidad de modificarlas. En el Japón los grupos de trabajo no se proponen una acción autónoma, que incluya la planeación, definición de ritmos de trabajo, ni la integración de la planeación con operaciones que se encuentran altamente estandarizadas".

11 En teoría la estrategia de la gestión de la calidad-JAT no se propone como un fin en sí mismo resolver el problema del enriquecimiento del trabajo, sólo busca involucrar a los trabajadores en las mejoras; cosa diferente se propusieron los proyectos adelantados en los años sesenta y setenta por la corriente sociotécnica, que explícitamente había cierta preocupación por hacer del trabajo una actividad enriquecedora para la cual la autonomía jugaba un papel importante. 
conocen las prácticas tradicionales de trabajo?

Seguidamente se explican las estrategias que adopta el nuevo trabajador cuando ingresa a la planta y se indaga qué supone trabajar en equipo, cómo afecta este tipo de organización las consideraciones sobre "trabajo justo" y "códigos morales de trabajo" y sus efectos, deseados o no, en la construcción de nuevas identidades o procesos de fragmentación entre los trabajadores.

\section{- La búsqueda de la aprobación en el centro de trabajo}

El trabajo es un ejercicio de adaptación y de aprendizaje, de resistencia y cooperación entre capital y trabajo y de relaciones de competencia y solidaridad entre los trabajadores. En el proceso de uso y de valorización de la fuerza de trabajo; el operario pone en acto sus potencialidades consistentes en habilidades, conocimientos y experiencias; también asume estrategias individuales que pueden ser contradictorias con las de la empresa y con las prácticas informales de los demás trabajadores. ${ }^{12}$

Si bien el intercambio mercantil le garantiza a la empresa la puesta en acto de la fuerza de trabajo del operario, no le asegura la potenciación máxima que re- clama ahora la estrategia de la calidad total-jat. Es en esta lucha entre la empresa y el trabajador por potenciar la fuerza de trabajo donde radica parte de la incertidumbre e impredecibilidad de esta particular relación mercantil. Si el trabajador no encuentra relaciones de reciprocidad no pondrá su fuerza de trabajo en potencia por tiempo ilimitado; realizará el trabajo designado y estará atento a la calidad pero no se mostrará necesariamente muy dispuesto a poner en potencia sus habilidades y conocimientos para mejorar los procesos productivos de manera continua.

Es por eso que aunque en apariencia no haya una lucha o conflicto abierto en los centros de trabajo, el conflicto estructural se expresa en que el trabajador puede hacer uso efectivo de ciertas herramientas de resistencia en su relación inmediata con el trabajo y con los trabajadores que estén dispuestos a asumir las demandas de la empresa sin cuestionamiento ni crítica. El mayor o menor uso de esas herramientas puede estar determinado por la existencia o no de una tradición o experiencia previa en sus usos, es decir, si alrededor del trabajo se han consolidado, de manera colectiva, terrenos de regulación y en especial con la mediación de la organización sindical. Si los

12 Para Weber" (1979: 66) debe entenderse que una relación social es de lucha cuando la acción se orienta por el propósito de imponer la propia voluntad contra la resistencia de la otra u otras partes" (1977, 31, Tomo I). La palabra lucha puede usarse para designar el comportamiento de directivos y trabajadores en la negociación del esfuerzo. En algunos casos, por ejemplo Burawoy, su uso se limita "a actividades que alteran las condiciones de la negociación del esfuerzo, la lucha altera el rendimiento relativo del capital y el trabajo, mientras que la competencia se refiere a actividades como los conflictos entre trabajadores que aceptan la distribución existente de beneficios....". 
cambios afectan intereses, costumbres o territorios valorados por los trabajadores, con el tiempo y de forma individual o colectiva los trabajadores asumirán dos estrategias. Si actúan según la primera pondrán en acto su fuerza de trabajo pero evitarán ponerla en potencia restando así eficacia a la pretensiones de la empresa; si escogen la segunda, de manera personal o grupal procurarán que su conducta sea seguida por los trabajadores.

Si bien bajo relaciones antagónicas esta lucha puede tener un carácter abierto, en contextos en donde el poder colectivo o individual es muy endeble, esa lucha estructural estará implícita; el trabajador nunca la abandona, siempre busca la forma de disminuir el poder real de la empresa sobre el uso de su fuerza de trabajo, ahí radica la imposibilidad del capital para controlar por completo a los trabajadores y saber efectivamente con qué cuenta. Esta impredecibilidad representa mayores retos para la dirección empresarial, le resta libertad para usar la fuerza de trabajo de forma ilimitada y sin ninguna contraprestación. Si la empresa quiere avanzar en la implementación de la gestión de la calidad tendrá que asumir estrategias persuasivas que se materialicen en relaciones de reciprocidad.

En la medida en que los conflictos abiertos son acallados, la lucha por conservar territorios y formas de trabajo asume formas individuales y colectivas, a la vez que se transfiere a las relaciones entre los trabajadores. Esta situación se observó más en Sofasa, Colmotores, Colgate y Textiles, todas ellas empresas con tradiciones de trabajo muy arraigadas y que contaban con un amplio contingente de temporales dispuestos a llevar a cabo los cambios.

En este apartado se quiere explicar y comprender cómo se insertan los nuevos contingentes en los centros de trabajo, es decir, cómo son su socialización y adaptación iniciales. Se tomará como ejemplo el caso de Colmotores porque no es muy distinto del de las otras empresas. Para una mayor comprensión de las relaciones en la planta se incluye el siguiente relato de uno de los trabajadores.

"Ingresé a principio de los noventa, como temporal y en calidad de operario a pesar de ser tecnólogo industrial y de realizar pruebas para ingresar como tecnólogo. Acepté el cargo de operario porque tenía muchas presiones económicas. El primer día pensé que no iba a ser capaz por el trabajo tan pesado. De 60 trabajadores que ingresamos ese día, ahora sólo quedamos tres. Incluso, algunos renunciaron a las dos o tres horas o el mismo día, decían que eso era "para burros". Me quedé por las garantías que daba la empresa y porque tenía muchas necesidades económicas, mi esposa estaba embarazada.

Cuando se llega a la planta todo mundo está sobre todo mundo, eso es una selva, el trabajador antiguo me escondía las herramientas, los materiales, los zapatos, me robaban la leche, nadie me ayudaba, los mandos medios nos trataban de malas maneras.

A pesar de la intensidad del trabajo, nunca pensé en largarme de aquí. Uno es berraco y es capaz, todo mundo estaba pendiente, querían saber si uno era berraquito o si no se va. Al principio uno se saciaba con el supervisor, procu- 
rando trabajar más de lo necesario, al final terminaba estallándose e incluso siendo rechazado por el grupo.

Uno se puede colgar en el trabajo porque no pidió el material a tiempo, porque los compañeros le esconden las herramientas. Al principio me hacían la vida imposible, después yo jalonaba la línea y ellos presionaban para que no fuera así, pero yo con eso ganaba respeto. Al final terminaba con los pies y las manos vueltos nada, terminaba rendido.

El jefe puede estar enterado del trato que uno recibe e, incluso, a veces lo fomenta. Cuando entré un compañero le guiño el ojo al supervisor y me colocó a realizar 120 unidades cuando en la practica me correspondían como 80 , es decir, me colocó a doblarme en la línea, con el apoyo de un operario, quien en la práctica era el que debía apoyarme.

"La prueba de agua" es el ritual de ingreso, consistente en que el trabajador nuevo debe salir a beber con los compañeros de trabajo y pagar la cuenta. A mi me han invitado y siempre me he negado. El que fuera a beber con ellos era porque era duro. De lo contrario, uno era un aliñado, no le colaboran, lo aíslan a uno. En una ocasión promovieron a un operario a supervisor y pidieron una cuota de $\$ 12.000$ para ir a un burdel a celebrarlo. Yo dije que no, que daba la cuota pero me iba para mi casa.

De todas formas, si uno es consecuente los compañeros terminan aceptándolo, es decir, aquí hay de todo: el alcohólico, el putas, el prostituto, lo importante es ser consecuente.

Uno debe hacerse ver también del jefe. En esa época, ellos tenían sus ahija- dos y protegidos, éstos los compensaban con regalos, invitándolos a comer y a beber por fuera de la empresa. Algunos le traían ollas de comida con pollo, yuca, papa y arepa, que el jefe recibía y se las llevaban para la casa".

Al ingresar a la empresa el trabajador vive un permanente estado de incertidumbre pues desconoce las reglas, costumbres y códigos de trabajo institucionalizados o acordados informalmente entre los grupos de operarios. Al asumir el código empresarial puede desconocer los acuerdos informales entre trabajadores y viceversa; ésta situación origina elecciones y tácticas diversas y cambiantes que responden a coyunturas, al proceso de aprendizaje, a las relaciones de poder establecidas en el centro de trabajo y a la interacción entre los actores. La elaboración y reelaboración de estrategias, entonces, se produce de acuerdo a condiciones concretas.

El trabajador nuevo busca la aprobación tanto del jefe como de los compañeros de trabajo para disminuir la posibilidad de exclusión o de cierre de relaciones sociales porque eso dificultaría su integración y permanencia en la empresa. Para los trabajadores antiguos el nuevo operario suele representar al "extraño", al que acepta, sin mayor resistencia, los cambio que impone la empresa y, en últimas, el que podría atentar contra las técnicas y prácticas sociales aprobadas por el grupo para hacer el trabajo, seguir los ritmos y aumentar los descansos. El nuevo operario es un "otro" al que los trabajadores antiguos no reconocen. Las actitudes y comportamientos de exclusión de los grupos de trabajo, la demarcación de territorios, las pruebas y trampas, respon- 
den, entonces, a la necesidad de descubrir quién es. Para incluirlo en el grupo es indispensable determinar su confiabilidad; las diferencias en el comportamiento por fuera de la jornada laboral no importan mucho, ni siquiera si acepta sólo en parte las rutinas de trabajo que el grupo ha aprobado. Los antiguos terminan tolerando las diferencias: que sea un "regalado", un "aliñado", aceptan, incluso que no asuma las reglas internas. Lo inaceptable es la delación de los códigos internos del grupo, eso implica la exclusión.

La lucha por conservar códigos y prácticas laborales, en especial las referidas a los ritmos y formas de trabajo, puede desencadenar enfrentamientos $y$ competencia entre los trabajadores. Por eso no basta que el trabajador gane el reconocimiento de su jefe inmediato, es necesario, además, que tenga la aprobación del grupo. Para eso tiene dos caminos: asumir las prácticas sociales del grupo, incluso, las de resistencia frente a la empresa, o redoblar esfuerzos para "hacerse ver" del jefe, tomando distancia del grupo a costa de que éste le retire parcialmente la cooperación. La búsqueda de la aprobación de los jefes y los compañeros de trabajo orienta las conductas del operario, por eso suele verse sometido a dos tipos de presiones: a las institucionalizadas por la estructura administrativa y a las institucionalizadas de manera informal por el grupo. El trabajador posee un margen de elección que utiliza de manera diversa.

Ganar la confianza y la aprobación de los compañeros de trabajo, sin "dejarse joder", suele ser el método del nuevo operario; pero también debe consentir, a la vez, con ciertos códigos grupales de trabajo y con las prácticas exigidas por la empresa, lo cual no siempre va en desmedro del rendimiento.

Ingresar a territorios demarcados, no sólo por la empresa sino por los mismos trabajadores, exige del trabajador novato capacidad de adaptación y de lucha. Su llegada a la planta no supone el establecimiento inmediato de relaciones de solidaridad con quienes se encuentran en similar situación de clase; su integración depende de la construcción de relaciones de confianza, basadas en el descubrimiento del "otro". Este proceso puede terminar en aceptación y respeto a las estrategias diferenciales asumidas por el "otro" que, entonces, empieza a ser el "compañero".

No hay una solidaridad de clase espontánea; ésta se va construyendo poco a poco en las relaciones cotidianas de trabajo, en la lucha contra la dirección empresarial por la defensa de intereses particulares y en el proceso de trabajo mismo que pone al descubierto la asimetría de poder entre empresa y trabajadores. Adaptarse es identificar los códigos de comunicación del grupo, es ganar claridad sobre los materiales, herramientas, ritmos y formas de trabajo, pero no sólo de los señalados por la dirección de la empresa sino de los establecidos informalmente por el grupo. La adaptación supone aprendizaje de formas de resistencia y de cooperación frente a la empresay de integración y competencia entre los trabajadores.

La primera etapa que cumple el nuevo trabajador es de adaptación y cooperación. Después, en la medida en que siente que sus esfuerzos no son bien compensados por la empresa, empieza a 
hacer resistencia; aprende a sopesar los ritmos de trabajo, a ganar descansos y a conformar poco a poco su propio grupo. La "caja negra" de la organización empieza a ser descubierta por el trabajador pero no por la alta dirección empresarial para la cual el mundo inmediato del trabajo es desconocido, y más aún cuando la empresa crece. El imperio del jefe o el "capataz" todavía subsiste; él conoce los "rituales de ingreso" y los ignora a propósito mientras no afecten de manera sustancial el rendimiento. Es más, suele favorecerlos porque como en este periodo el trabajador busca sobre todo su aprobación, redobla esfuerzos como prueba que acata las exigencias de la empresa.

En medio de fuertes cambios organizativos, los "rituales de ingreso" no sólo son una prolongación de las pruebas de selección, sino formas de resistencia de los trabajadores antiguos que intentan conservar las prácticas tradicionales de trabajo en tanto la empresa presiona al nuevo trabajador para que las desconozca; los operarios antiguos demandan del nuevo capacidad para sobrevivir a las prácticas de integración-exclusión y lucha-competencia que se dan en el centro de trabajo, además de las presiones propias del sistema de dominación y trabajo fabril.

En Colmotores, lo mismo que en las otras empresas estudiadas, el sindicato no suele intervenir en el proceso de adaptación del trabajador. Los conflictos se resuelven en el grupo, con el visto bueno o la indiferencia del jefe inmediato. En empresas sometidas a procesos de reestructuración -vinculados a la estrategia de la calidad total-JAT- los trabajadores jó- venes, recién ingresados, suelen ser objeto de mayor presión porque la dirección empresarial aprovecha su inexperiencia para redefinir e intensificar formas de trabajo; eso ha ocurrido en Sofas, Colmotores, Colgate y en parte en Textiles. Los trabajadores antiguos se protegen de la intensificación defendiendo sus prácticas, por eso necesitan la lealtad del nuevo trabajador y para garantizarla recurren a medios persuasivos, al retiro de la cooperación o a su exclusión.

Estas prácticas suelen ser más frecuentes en las empresas donde la resistencia de los trabajadores está más consolidada, hay estructuras de trabajo poco flexibles, prácticas de territorialidad muy arraigadas entre los trabajadores y fuertes procesos de reestructuración empresarial. En esta situación la empresa acude a personal externo para implantarlo rápidamente lo cual atenta contra las costumbres laborales y contractuales que existen de hecho. En estos casos los nuevos trabajadores se convierten en actores "materializadores del cambio". En conclusión, el trabajador recién ingresado se ve presionado a materializar los cambios organizativos con el costo de enfrentar la lucha y competencia de sus propios compañeros. Esta lucha no atenta contra el rendimiento, por el contrario, lo garantiza en la medida en que el trabajador termina dando más del promedio esperado como condición de permanencia.

\section{- La negociación informal del traba- jo justo}

"Lo bueno de los cambios es que podemos ser más participativos y que se aprende más. Lo malo es que nos va a 
tocar trabajar más y que va a haber rechazo hacia las personas nuevas que no rindan" (entrevista, operario Colmotores).

El ritmo del trabajo era uno de los pocos terrenos regulados de manera informal por las organizaciones sindicales en Sofasa, Colmotores y Cementos; en otras empresas la costumbre institucionalizó las prácticas de trabajo y les confirió aceptabilidad. Los procesos de reestructuración no sólo han replanteado las formas y contenidos de trabajo sino su ritmo, elemento generador de conflicto abierto o implícito en todas las empresas estudiadas. A través del caso de Colmotores el análisis puede hacerse más comprensivo.

La elevación de la intensidad del trabajo en la mayoría de las empresas estudiadas obedeció a dos razones fundamentales: al rebalanceo de las líneas y al aumento de tareas indirectas asumidas por los operarios. El número de trabajadores por estación no se aumentó, al contrario, en la practica disminuyó. La gran mayoría de los operarios que hacen parte de los grupos de trabajo son temporales cuya antigüedad oscila entre unos meses y diez años. El grupo de operarios antiguos o permanentes, hoy minoría en empresas como Colmotores, está diseminado por toda la planta y es difícil que haga mayoría en un equipo. Los trabajadores participaron en el balanceo de las estaciones que requirió el trabajo en grupo, bien sea en células o en la línea. El mayor ritmo de trabajo que desplegaron los operarios temporales sirvió de parámetro para que algunas estaciones fueron ajustadas y se elevara con reiteración el ritmo general.
El criterio de ritmo "justo" del trabajo es distinto para los trabajadores permanentes y los temporales. Por ejemplo, para un trabajador antiguo de Colmotores lo justo es ensamblar cinco vehículos diarios, para uno temporal ensamblar seis es pesado pero soportable. No le parece "injusto" porque, primero, su organismo tiene más capacidad de resistencia y de recuperación; segundo, carece de experiencia de trabajo para hacer comparaciones; tercero, desconoce variables que inciden en los ritmos de trabajo -contar con el material a tiempo, daños de los equipos, rectificación de partes- $y$, cuarto, su precariedad es mayor respecto a la de los trabajadores permanentes. Así, el trabajador temporal termina contribuyendo a la intensificación del trabajo.

Su juventud, energía e "incansabilidad" hacen que trabaje a ritmos superiores al promedio sin que le importe que al final de la jornada esté agotado. Ellos mismos se sorprenden de su rápida recuperación; la edad y el deseo de permanencia son los mejores soportes para el esfuerzo. A otros jóvenes operarios el deseo de evadirse mentalmente del trabajo, de no pensar en su situación actual, de sentir que están ocupados los presiona a desplegar su capacidad de trabajo de manera incansable, superando el promedio de trabajo. Varios operarios narraron algo parecido a lo siguiente:

"Aprendí a trabajar más de las estaciones normales, el tiempo se hace largo, tedioso, tengo que estar haciendo algo, al final terminaba con las manos y los pies vueltos nada, terminaba rendido. El trabajo se convierte como en una droga" (Joven trabajador temporal, Colmotores). 
De esta conducta resulta la elevación de los ritmos de trabajo aunque esa no haya sido la intención de los trabajadores temporales; es un resultado no esperado, un efecto, incluso, no deseado.

"Una vez me tomaron el tiempo y me gasté 18 minutos. Unos compañeros me dijeron que la había embarrado y eso me sirvió de experiencia, posteriormente lo he hecho en 30 ó 40 minutos. Eso depende del jefe y de la efectividad de cada operario. Aquí todos los tiempos son iguales, a veces yo acabo mi trabajo en 20 minutos y voy a ayudarle a otro compañero, me gusta siempre estar haciendo algo, el tiempo pasa más rápido" (Joven trabajador temporal, Colmotores).

El deseo de permanecer en la empresa impulsa al temporal a aceptar, sin mayor discusión, el aumento de los ritmos de trabajo. Además, como carece de experiencia, todavía no calcula ni el costo físico que ese esfuerzo tendrá en el futuro, ni la presión que recibirá de los trabajadores permanentes. Cuando ingresaron a la empresa los trabajadores antiguos y los actuales temporales asumieron prácticas similares pero, poco a poco, empezaron a sopesar los ritmos de trabajo y a prever, por ejemplo, que la producción tiene un alto grado de incertidumbre, que el material no llega a tiempo o que el equipo puede presentar problemas, situaciones a las que los ingenieros no les prestan suficiente atención cuando realizan cálculos de tiempo por operación. Aprenden también que los años, como dicen, "no vienen solos", que no es un problema de disposición sino que el cuerpo "pasa factura de cobro" por los excesos pasados, que hacer ciertos movimientos ya implica mayor dificultad, que el agotamiento llega pronto si los ritmos se intensifican y si el trabajo no se realiza con técnica.

"Hay más presión, ha aumentado el ritmo de trabajo. Llega un joven que está trabajando conmigo y de pronto me gana. Pero un muchacho es incansable, uno se desgasta" (trabajador antiguo, Colmotores).

El trabajador antiguo pierde vitalidad, ya no es incansable; el trabajo le ha arrebatado parte de su juventud. Trabajar con técnica le permite rendir al mismo tiempo pero no al mismo ritmo que los jóvenes. Un jefe comentaba:

"Con los antiguos siempre hay problemas, luchan contra el proceso de cambio, llegan tarde o se van antes, el temporal es más dado a colaborar, el antiguo lo hace a su juicio, lo que él considera como justo".

Esta misma situación se halló en Sofasa, un RU la relata de la siguiente manera:

"El cambio de personal es del $80 \%$. Se ha ido concienciando al personal nuevo de la necesidad de atacar las fallas. Es un personal que no critica los cambios, se adapta fácilmente. Anteriormente el trabajador hacia mucho su parecer. Decía 'estoy cansado, me voy', sin tener en cuenta la productividad. [En ese momento llega un operario joven quejándose de otro que se marcha porque considera que él ya ha terminado su trabajo]. Este caso, dice el RU, es el caso de un señor de 18 años de antigüedad que se marcha, esta gente es muy difícil. Los afectados son los trabajadores nuevos porque él se va y deja todo el trabajo a los nuevos. El antiguo nota las 
diferencias. Anteriormente contaban con un espacio de tiempo para desacalorarse y bañarse. Incluso si terminaban antes podían parar y descansar, eso sí no podían salir antes de la hora señalada por el turno. Ahora hay mucho trabajo y estos tiempos han desaparecido o se han acortado. Nosotros simplemente informamos a los RG, ellos tienen mano fuerte. Pero primero se entra en términos de diálogo, para que el trabajador exponga sus argumentos".

El trabajador antiguo está cada vez menos motivado para permanecer en una empresa en la que su trabajo ya no es valorado. El saberse marginado, carente de reconocimiento personal, juzgado porque sus peticiones, que él considera "justas", son vistas como un problema de disposición personal, le generan desgano frente al trabajo. Él, a diferencia del temporal, ha contribuido a la configuración de lo que hasta ese momento significaba un "trabajo justo"; para el trabajador antiguo asumir nuevas tareas debe significar mayor retribución, éstas no deben aceptarse por el temor a la desaprobación. Aunque cada vez menos escuchados, siguen protestando:

"Explotan al temporal, ellos están en contrato, trabajan sin derecho a decir no lo hago. No se puede refutar. Cuando hay antigüedad uno defiende más sus derechos. De lo contrario, trabaja y obedece por temor. En mi caso yo no soy temporal, uno tiene más seguridad, tiene más cancha. No le da temor refutar al jefe" (trabajador permanente, Colmotores).

Un joven trabajador de Sofasa narra su situación:

"Sí, estamos muy cansados ... uno desarrolla la habilidad de adelantarse un poquito y descansar 3 o 4 minutos. Muchas veces con un minutico que uno se sienta coge impulso. Si estamos muy cansados uno no puede decir porque ellos tienen muchas cosas que atender -jefes-. Lo único que puede hacer uno es trabajar. La única ventaja es que no trabajamos sábados y domingos... Si fuera de lunes a sábado este ritmo no lo aguanta nadie. Tendrían que cambiar de personal cada dos o tres años porque el agotamiento es tremendo. Si muchas veces el sábado y el domingo no alcanzan, llega uno el lunes doliéndole todo".

A medida que pasa el tiempo, el trabajador temporal empieza, como los antiguos, a regular su capacidad de trabajo; aún así, la consideración diferencial del "trabajo justo" divide a los trabajadores jóvenes y los más antiguos, es una de las razones de la fragmentación. El nuevo aprende que puede, por ejemplo, realizar una estación no en los 40 minutos programados sino en 30 , pero que ese tiempo es extraordinario, que no puede prolongar los ritmos por extensos espacios de tiempo. La incertidumbre laboral, además, termina por desgastar su disposición frente al trabajo. Algunos se limitan a realizar lo que la empresa ordena, es decir, a una cooperación básica. Un supervisor de Colmotores reconoce este problema en los siguientes términos:

"Yo pienso en los muchachos de ahora, la incertidumbre laboral no los deja trabajar tranquilos, ellos no pueden asumir ningún riesgo en su vida personal. Con el tiempo, los temporales empiezan a bajar el ritmo y uno, como supervisor, a motivarlos. No hacen más allá de lo que les corresponde". 
En resumen, lo que los trabajadores consideren un trabajo justo está asociado a la costumbre, que se convierte en parámetro de medición; a la capacidad física promedio de los trabajadores para desplegar su fuerza de trabajo y a las compensaciones positivas ligadas a estabilidad laboral y económica y al reconocimiento, entre otros. La definición de "trabajo justo" también es el resultado de los acuerdos y desacuerdos entre trabajadores y directivos empresariales.

Las organizaciones sindicales fueron debilitadas y excluidas y perdieron poder de regulación en cuanto a la intensificación del trabajo; pareciera que deja de ser un conflicto institucionalizado en el que la mediación sindical tiene validez y eficacia relativa. El conflicto por los ritmos de trabajo parece silenciado por el temor y por un sentimiento de impotencia. El silencio no significa ausencia de conflicto sino el reconocimiento de una debilidad de negociación en esos terrenos. Sólo queda la opción informal: buscar maneras de trabajar que reduzcan su intensidad o establecer formas de cooperación en el ámbito grupal; en todo caso terminan contribuyendo al rendimiento.

\section{- Redefinición de códigos laborales}

En las empresas estudiadas donde se sustituyó el trabajo en línea por el tra- bajo en grupo, fueron modificadas las relaciones sociales entre los trabajadores, sus roles y sus códigos de trabajo. Los códigos morales de un importante grupo de obreros se trastocaron porque debían llegar a acuerdos con la empresa sobre cómo trabajar, cómo distribuir las tareas, cómo cooperar y cómo negociar el esfuerzo ${ }^{13}$.

El trabajo individual, en línea, está basado en el lema "sálvese quien pueda". Cada operario recurre a estrategias diferentes para salvar escollos en el trabajo, bien sea apelando a sus vínculos personales con el jefe inmediato o acudiendo a un compañero en busca de apoyo. Estos compromisos o solidaridades no dependen de acuerdos y costumbres grupales sino de las relaciones personales de cada trabajador. Aún así, el trabajo en línea también configura un código moral que abarca aspectos como el respeto a los ritmos de trabajo soportados y permitidos colectivamente y la práctica del encubrimiento mutuo. La delación del otro, y en especial de las prácticas colectivas informales, es sancionada como algo sucio. El encubrimiento mutuo de prácticas censuradas por la dirección empresarial permite la construcción de cierta identidad colectiva entre los trabajadores; estas faltas no atentan de manera drástica contra el rendimiento, es más, es posible que el

13 Baldamus citado por Edwards (1990:18), indica que "la negociación del esfuerzo es un concepto útil como puente entre el análisis de las bases del conflicto y la consideración del comportamiento concreto; uno de los argumentos clave de Baldamus, a saber, que el contrato de trabajo nunca puede especificarse totalmente por anticipado (...) existe necesariamente una incertidumbre sobre el modo en que se transforma en trabajo efectivo o "esfuerzo", como él lo domina capacidad de trabajo de los trabajadores". 
jefe inmediato las conozca pero prefiera desentenderse del asunto mientras no perjudique demasiado el rendimiento.

La nueva forma de trabajo en grupo implica la asunción de un nuevo código moral que se va configurando con las prácticas de trabajo cotidianas, con los conflictos y sus formas de resolución. Aunque éste código moral no siempre es asumido por todos y cada uno de los miembros del grupo su incumplimiento supone la presión del grupo sobre el infractor. Este código contempla la cantidad de producción que el grupo está colectivamente dispuesto a realizar, los ritmos promedio de trabajo y las responsabilidades que decidió asumir sin que su ejecución levante sospechas sobre quien las ejecute. Supone también el secreto sobre prácticas que suelen distanciarse de las formas de trabajo determinadas por la empresa pero que, al entender del trabajador, le permiten un trabajo más descansado o que se han hecho costumbre. También involucra el secreto sobre acciones para lograr ritmos de trabajo que el grupo considera "justos", lo cual incluye los descansos aprobados en colectivo. La delación de estas prácticas es tan censurable como no cooperar en el trabajo y atentar así contra el rendimiento y la calidad. No estar atento a la calidad y no trabajar en equipo para responder por la producción acordada, es reprochado no sólo por el jefe sino por el grupo, que se ve afectado por el incumplimiento de uno de sus miembros.

"Cuando llega una persona mala, toca llamarla al orden. Nos reunimos los cinco compañeros y decimos aquel se está haciendo el marrano, digámosle sin ofenderlo. Por ejemplo: usted vino a tra- bajar con nosotros si tiene que hacer una llamada u orinar, lo reemplazamos pero si se va a hacer cuatro llamadas no lo reemplazamos. También le decimos usted está cogiendo el equipo de soldadura mal, cójalo así para que las cosas salgan mejor" (operario antiguo, Colmotores).

Las responsabilidades adquiridas en el puesto de trabajo y los nuevos conocimientos técnicos están cada vez más integrados en un código solidario; éstos atributos proporcionan a los integrantes del grupo cierta autonomía en su trabajo y poder para resistir los deseos de sus jefes, a pesar de que la rigidez del trabajo en línea deja pocos espacios.

El código moral de los trabajadores no exige una relación distante o conflictiva con el jefe inmediato, a éste se le trata con informalidad pero sobre la base de la dignidad y respetabilidad; el mal trato es menos soportable que en el pasado inmediato. Además, hay que considerar que los supervisores, antiguos operarios, se han visto obligados a cambiar sus prácticas autoritarias; se acercan al trabajador con una actitud persuasiva, lejana del enfrentamiento permanente tan habitual diez años atrás.

No obstante, es necesario destacar que en empresas como Textiles en donde el salario estuvo ligado al aprendizaje del número de oficios, la redefinición de códigos de trabajo, las solidaridades y espacios de autonomía alcanzados por los grupos tuvo un carácter cerrado y excluyente, hasta el extremo de reforzar las prácticas de exclusión de la empresa con los trabajadores que no estaban dispuestos a involucrarse sin cuestionamiento ni crítica; esto se tradujo en la conformación 
de grupos bastante homogéneos, normalmente formados por jóvenes trabajadores con mayor escolaridad. Uno de ellos relataba:

"Si de pronto un compañero no nos gusta, lo despachamos. Si todos somos buenos le va bien a la unidad, pero si hay dos buenos y tres malos la unidad no funciona. Hablamos con el supervisor para que cambiara al trabajador que no rinda, era muy incómodo pero tenía que ser así en toda la planta... Era mejor que los viejitos trabajaran solos porque no podían moverse con agilidad, ni subirse a una escalera, era mejor trabajar con personas con buenos alientos, ágiles, que no se fueran a caer" (Líder de grupo, Textiles).

Las diferencias entre antiguos y temporales terminan por generar solidaridades de grupo más que colectivas -en el sentido de la totalidad. La presencia de los temporales ha facilitado los procesos de reestructuración y evitado a las empresas asumir compensaciones positivas. Estos trabajadores suelen ser receptivos a las propuestas organizativas y se muestran dispuestos a cooperar sin reclamar cualquier tipo de negociación.

Es posible que con el tiempo los trabajadores temporales aprendan a medir su rendimiento y surjan solidaridades entre el conjunto de los trabajadores; hasta el momento hay mucho temor, el poder que demostró la empresa (caso Sofasa y Colmotores, por ejemplo) lesionó la credibilidad, no sólo en la organización sindical sino en la empresa misma.

Burawoy afirma que al ingresar en la planta el operario entra en una especie de juego que lo obliga a "arreglárselas" para permanecer en él. Es un juego es- tructurado por normas, costumbres y convenciones preestablecidas que configuran una forma de dominación. Sólo ingresar al juego supone la aceptación de las reglas básicas con las cuales hay que jugar, supone consentir, disciplinarse $y$, por lo tanto, apostarle a los fines del capital y al rendimiento como condición de permanencia. Cómo jugar y qué jugadas hacer en un momento determinado son cuestiones individuales más que colectivas; además, aunque el trabajador elabore estrategias para aprovechar el estrecho margen de acción, los resultados de sus jugadas no siempre responden a sus intenciones. En esta búsqueda de "arreglárselas" hay permanentes encuentros y desencuentros, tanto con los jefes como con los compañeros de trabajo. Habría que resaltar que las normas son reinterpretadas y construidas socialmente, en este sentido son negociadas.

La reestructuración del proceso productivo presionó a la dirección empresarial de las empresas estudiadas a replantear las reglas del juego, aunque no sus fines. Para obligar a los trabajadores a entrar en el juego han usado acciones persuasivas y coercitivas. Es un proceso de dominación y aprendizaje en el que se redefinen espacios y terrenos de regulación que permiten a los trabajadores canalizar en su provecho limitadas oportunidades y a la empresa racionalizar cada vez más los procesos desde el punto de vista de la calculabilidad y reducción de costos.

El ingreso de nuevos jugadores que desconocen las reglas ha propiciado el cambio de las reglas de juego y ha fragmentado aún más a los trabajadores. En este orden los conflictos no suelen dirigir- 
se, abierta y colectivamente, contra las nuevas reglas del juego. En un ambiente de alta inestabilidad laboral y con un poder de negociación institucionalizado muy frágil, a los trabajadores, en especial a los antiguos, sólo les queda la opción de llegar a acuerdos con los temporales sobre qué es "trabajo justo" y las formas de desplegar la fuerza de trabajo para contrarrestar su intensificación. Ya no pueden oponerse al rendimiento como tal. Como la inconformidad no tiene una expresión colectiva no se generan procesos de institucionalización y regulación que incluyan los intereses de la empresa y de los trabajadores.

\section{Relaciones de reciprocidad}

Teórica y empíricamente para avanzar de manera coherente y eficaz sobre estrategias vinculadas a la gestión de la calidad-jat se requiere establecer relaciones de reciprocidad o corresponsabilidad entre capital y trabajo, base fundamental para construir o reconstruir relaciones de confianza entre las partes, pues como lo sugiere una de las conclusiones de Kochan, Katz y MacKersie (1993: 242) en su estudio sobre La transformación de las relaciones laborales en los Estados Unidos:

"El éxito de los programas de calidad... y de otros intentos de reforma depende de la capacidad de la organización de reforzar y mantener un alto nivel de confianza. ... el mantenimiento de un clima de confianza dependerá fuertemente de la medida en que las estrategias y acontecimientos registrados en los niveles superiores del sistema de relaciones laborales estén en conformidad y en vinculación con el crecimiento de la confianza en el lugar de trabajo. ... la implicación en este nivel superior resultó decisiva, ya que significaba que la participación de los sindicatos y trabajadores no era un paso para acabar con la representación sindical y contribuyó a convencer a los trabajadores y al sindicato de que de esta manera se conseguirían una mayor seguridad de empleo... esta expansión sólo se presenta cuando los sindicatos son fuertes y se sienten relativamente seguros... para que la participación de los trabajadores se mantenga eficazmente a lo largo del tiempo se requiere como condición imprescindible la implicación de los mismos en las decisiones estratégicas, pero por la otra se requiere también ineludiblemente un sindicato fuerte y dispuesto a colaborar....".

Las relaciones de confianza entre la dirección empresarial y los trabajadores se sustentan en relaciones de reciprocidad y corresponsabilidad, lo cual demanda entre otras condiciones:

- Fuerte compromiso de la alta dirección y de su cuadro técnico para adelantar los cambios en la gestión de la mano de obra los cuales, a su vez, les exigen estar dispuestos a ceder poder, ampliar los márgenes de participación individual y colectiva de los trabajadores y asumir responsabilidades laborales frente a la mano de obra $^{14}$-en especial las vinculadas a estabilidad y calificación- (Kochan et al., 1992: 173 y 1997: 306).

- Niveles altos de motivación, compromiso y confianza en las relaciones de empleo. Las estrategias competitivas que enfatizan en los costos y los sala- 
rios bajos producen niveles altos de conflicto, refuerzan las relaciones de baja confianza entre empresarios y trabajadores e inhiben la innovación y las mejoras en la calidad (Kochan y Useem, 1992: 176).

- Sólida institucionalización de las organizaciones sindicales a nivel de lo social y de las empresas, lo que supone la existencia de sindicatos fuertes, dispuestos a negociar y a comprometerse con los cambios.

Es claro que las empresas estudiadas carecen de estas condiciones, situación que le resta eficiencia y eficacia a mediano y largo plazo a la estrategia de calidad-jat. La reestructuración empresarial se apoya en marcos económicos, sociales y políticos muy inestables. Los trabajadores que hasta hace algunos años se sentían protegidos ya no lo están, la angustia empieza a embargarlos. La dirección empresarial encuentra en el temor al despido un ambiente propicio para la reestructuración; pero no advierte que esa forma de trabajo es más una "resignada aceptación que un compromiso positivo" que garantiza la cooperación básica y que no alcanza a poner en acción las potencialidades de los trabajadores para el logro del rendimiento.

La reestructuración no concertada está lejos de un real involucramiento de los trabajadores, está construida desde arriba, distante de un proyecto colectivo que conjugue tanto las formas de obtener el rendimiento como de distribuirlo.

\section{Un trabajador precario ¿Sobre quién la responsabilidad?}

El peso que tiene hoy el mercado, concomitante con la debilidad del Estado y la ausencia de instituciones adecuadas de apoyo a las estrategias empresariales, le restan eficacia a dichas estrategias, esta situación presiona a las empresas a mantener las políticas de reducción de costos laborales cuyos efectos negativos recaen en especial sobre los trabajadores acrecentando su estado de precariedad.

La precariedad es una condición del trabajador y no del trabajo; la precariedad despoja al trabajador de autonomía y libertad, lo reduce a un estado de "individualismo negativo" definido en "términos de falta: falta de consideración, falta de seguridad, falta de bienes segurosy vínculos estables" (Castel, 1995: 469). Un trabajador precario que se desenvuelve en el marco de relaciones individualizadas y que carece de apoyos colectivos, oscurece los conflictos o silencia actores

14 Kanter citado por (Kochan et al., 1993: 287) identifica dos tendencias firmes en los valores reconocidos por los trabajadores: Primero, la expectativa creciente de que el trabajo se convertirá en fuente de autoestima, recompensas no materiales y oportunidades constantes de desarrollo personal. Segundo, la conciencia y disposición cada vez más fuertes a reivindicaciones relativas a la instauración de los derechos individuales, la justicia y la igualdad en sus puestos de trabajo. ... no desplazan, sino más bien amplían las expectativas básicas ...las necesidades de recompensas materiales: ingresos, higiene y salud y seguridad del empleo. 
que, con el respaldo de colectivos identitarios, tendrían voz, tendrían palabra.

La ausencia de movimientos sindicales fuertes y legítimos, que convoquen a los trabajadores a luchar y a construir redes de solidaridad social para contener la desigualdad de los efectos negativos de la reestructuración, tiene como consecuencia que los conflictos tiendan a ser oscurecidos; por ahora el estado de precariedad del trabajador no se traduce en un resentimiento individual o colectivo que agrave la frágil cohesión social que existen en el país (Castel, 1995:22) ${ }^{15}$.

La precariedad del trabajador es una situación que se extiende cada vez a un mayor contingente. Ahora no sólo se siente inestable quien tiene un trabajo temporal sino el que goza de un contrato estable, más aún, hasta el que asume una conducta disciplinada. Un trabajador de Cementos con contrato a término indefinido transmite esta situación y sensación de precariedad:

"Si uno que nunca ha tenido problemas, ha cumplido con sus deberes, ni viene borracho, ni es grosero, a pesar de eso, uno vive con temor, piensa puede ser hoy o será mañana, a veces llego a la casa preocupado. Uno debe prepararse, ....".
La existencia de las empresas está permanentemente amenazada por la violencia política y social del país y por el mercado como institución reguladora de la economía. En este contexto la responsabilidad o culpa por los efectos negativos de la reestructuración sobre los trabajadores suele tomar dos formas. La primera transfiere las responsabilidades de las políticas de ajuste de mano de obra a condiciones externas que rebasan la responsabilidad empresarial, más aún, desde esta perspectiva el empresario se ve sometido a las fuerzas del mercado y no tiene mayores márgenes de actuación a favor de los trabajadores. De esta forma se legitiman políticas de reducción de costos laborales, de intensificación del trabajo y de descentralización de actividades. Por tanto, perder el trabajo, como le sucede a amplios contingentes de obreros, no es siempre responsabilidad empresarial ni del individuo, de su poca disposición a disciplinarse o adaptarse a un orden empresarial determinado.

Visto así, la empresa, los trabajadores y los sindicatos parecen estar sujetos a un mismo mal que escapa de sus posibilidades de actuar, incluso, a favor de ellos mismos. La empresa busca el respaldo de los trabajadores y del sindi-

15 "Pero los supernumerarios no son siquiera explotados: para serlo hay que tener pericias convertibles en valores sociales. Son superfetatorios. No se advierte cómo podrían representar una fuerza de presión, un potencial de lucha, puesto que no gravitan en ningún sector neurálgico de la vida social. Sin duda, de este modo se inaugura una problemática teórica y práctica. Si ya no son "actores" en el sentido propio del término, porque no hacen nada socialmente útil, ¿cómo podrán existir socialmente? Desde luego, por "existir socialmente" entendemos ocupar un lugar en la sociedad. Pues, al mismo tiempo, están muy presentes, y éste es todo el problema, ya que están de más" (Castel, 1995:22). 
cato para adelantar el proyecto de modernización y reestructuración porque sus efectos negativos parecen escapar a su intencionalidad. El gran dilema es ¿sobre quién o quiénes deben recaer los costos de la reestructuración? Es claro que las empresas son cada vez más frágiles, que la compensación de sus esfuerzos suele ser transitoria en términos de rendimiento, que se requiere un contexto económico y político diferente al que promueven en la actualidad las políticas neoliberales y la alucinante violencia que recorre el país. Pero es claro también que hasta ahora los principales afectados por la reestructuración han sido los trabajadores quienes han perdido las escasas protecciones colectivas que tenían, como resultado de la presión del capital. En este sentido, De la Garza afirma (2004:24):

"La decadencia del movimiento obrero se debe principalmente al triunfo de las estrategias de los empresarios para ganarse a los trabajadores y hacerles ver que su enemigo no es el capital sino las empresas competidoras en el mercado, también a la transformación del Estado hacia el neoliberalismo que ha reducido espacios de acción de los sindicatos y ha apoyado a las empresas en la flexibilización de los mercados de trabajo".

La segunda forma muestra a un trabajador que suele ver su situación de precariedad como una relación ambivalente. Por un lado, la estabilidad no depende de su conducta individual, pero de ningún modo está seguro, carece de vínculos estables, es decir, llega a una situación de "individualismo negativo". Pero, a pesar de saber que su situación no depende de sí mismo, el trabajo permanentemente inestable y mal remunerado termina vien- do afectada su autoestima personal. El trabajador sometido a estas condiciones concluye que su situación individual es un problema personal y eso le resta capacidad de actuación y agudiza su disposición a subordinarse, a silenciarse.

Sin embargo, en estos tiempos de incertidumbre y de violencia, el conflicto industrial puede tomar rumbos inimaginados, puede llegar al silenciamiento de los trabajadores, como hemos visto hasta ahora, o a una explosión de resentimiento de individuos sin vínculos, sin autonomía y sin protecciones, que agrave aún más la situación de violencia del país. Individuos en tránsito continuo, para los cuales la fábrica es un lugar de paso que no logra definir identidades sociales ni profesionales. Sujetos $\sin$ mayores cohesiones sociales indispensables para la consolidación de un orden social.

\section{Conclusiones}

Podemos concluir que para el estudio del caso colombiano de los cambios en las relaciones laborales y en el trabajo, el marco analítico del M.I.T. es pertinente en varios sentidos. Primero, las empresas sí juegan un papel estratégico en la configuración de las relaciones laborales, siendo éste el ámbito de estudio central para la comprensión y explicación de los cambios; sin desestimar el vínculo que debe establecerse entre las esferas meso de las relaciones laborales y macro de los campos económico, social, laboral y político. Segundo, si bien, las instituciones son estructuras que determinan y configuran la acción de los sujetos, éstos también son actores que con sus acciones contribuyen a la configuración y 
transformación de las estructuras sociales, de ahí que es indispensable abordar los estudios laborales desde el campo de las estrategias de los actores, estableciendo vínculos entre el actor y las instituciones. Tercero, la reconstrucción histórica de los procesos se muestra no sólo pertinente sino fundamental. Cuarto, sin embargo, este marco analítico presenta un vacío importante; debería contemplar la esfera política, dado el influjo que ejerce ésta en la construcción de las mentalidades de los actores empresariales -dirección empresarial, trabajadores y organizaciones sindicales-.

Respecto al concepto de estrategia, como tácitamente lo propone el equipo del M.I.T., no debe ser abordado desde una perspectiva clásica el modelo racional de toma de decisiones que se apoya en supuestos tales como: a) el sujeto examina todos los posibles cursos de acción; b) el sujeto construye todos los futuros escenarios a los que llevaría cada alternativa examinada; y c) el sujeto compara estos escenarios futuros y selecciona aquel que maximice su función de utilidad. Además, supone que se cuenta con información completa y que el sujeto conoce sus preferencias y que éstas son estables, es decir, no serán alteradas en el futuro (Vergara, 1997: 12). Se propone, primero, considerar que el actor (empresario, directivo, trabajador o líder sindical) es un actor que interactúa con el otro y que su comportamiento se explica por los intereses que contrae al ocupar posiciones estructuralmente relacionadas ${ }^{16}$. Segundo, uno de los elementos centrales del concepto de opciones estratégicas se sustenta en el margen de variación de los recursos tácticos de los que disponen los actores empresariales y no tanto en los objetivos estratégicos mismos (que pueden no existir en cuanto tales). En este sentido apunta los aportes realizados por Crozier y Friedeberg (1990) quienes señalan que para entender el concepto de estrategia son necesarias las siguientes consideraciones: el actor rara vez tiene objetivos claros y menos todavía proyectos coherentes, estos son más o menos explícitos y más o menos contradictorios. En lugar de ser racional con arreglo a ciertos objetivos lo es, por una parte, en relación con las oportunidades y a través de éstas con el contexto que las defina y, por otra, en relación con el comportamiento de los otros actores, con el partido que toman y con el juego que se establece entre ellos. Por último, habría que señalar que aunque las acciones de los actores empresariales pueden desencadenar en actos no deseados ni planeados por ellos, parafraseando a Aguiar, las estrategias de la dirección empresarial no abandonan su carácter normativo, esto es, se preguntan siempre por los mejores

16 Gil Calvo (1993: 237) señala: "Los intereses que determinan los actos ni son propios de los individuos ni tampoco siquiera de las posiciones que éstos ocupan: sino más bien de las relaciones sociales de interdependencia recíproca que se establecen estructuralmente entre unas posiciones y otras". 
medios para obtener unos fines dados dejando a un lado la racionalidad de los fines mismos (1993: 350).

Finalmente, no sobra reiterar, primero, que efectivamente las puesta en marcha de la estrategia empresarial de la gestión de la calidad-jat en la industria colombiana, en los casos analizados, directa e indirectamente, sí contribuyó a la transformación de las relaciones laborales y del trabajo. Segundo, que ésta tuvo un efecto mayor en aquellas empresas en donde había una tradición de relaciones de baja confianza entre capital y trabajo. Tercero, que dicha estrategia fue filtrada por las relaciones laborales previamente existentes; por las mentalidades de los actores empresariales; por las estrategias individuales y colectivas de los trabajadores; y en especial por el contexto político y económico en que se adelanta dicha estrategia. $Y$ cuarto, las relaciones antagónicas de clase son desplazadas en todos los casos estudiados mientras las relaciones neopaternalistas ganan espacios en los contextos empresariales en donde se adelanta la estrategia de la calidad total-jat.

\section{Referencias Bibliográficas}

\section{Burawoy, Michel (1989). El consentimiento} en la producción: los cambios del proceso productivo en el capitalismo monopolista. Ministerio de Trabajo y Seguridad Social. Madrid, España.

Cárdenas, Miguel Eduardo (edt.). (2006). "Treinta años de sindicalismo en Colombia: vicisitudes de una transformación", en: Leal Buitrago, F., En La encrucijada. Colombia en el siglo XXI, Bogotá, Grupo editorial Norma.
Castel, Robert (1995). Las metamorfosis de la cuestión social, una crónica del salariado. Paidos, Estado y Sociedad, México.

Crozier y Friedeberg (1990). El actor y el sistema, España.

Chandler, Alfred Jr. (1988). "La mano visible, la revolución en la dirección de la empresa norteamericana", Ministerio de Trabajo y Seguridad Social de España, Madrid.

De la Garza, Enrique (2004). Alternativas sindicales para América Latina, ENS.

Garrido, Medina, Luis, Gil, Calvo, Enrique (eds.), (1993). "Estrategias familiares", Alianza Editorial, España.

Garay, Jorge et al. (1998). "Colombia: estructura industrial e internacionalización 1967-1996", Programa de Estudio la industria de América Latina ante la globalización económica, DNP, Colciencias, Consejería Económica y de Competitividad, Ministerio de Comercio Exterior, Ministerio de Hacienda y Crédito Público y Proexport Colombia, Bogotá.

Kochan, Thomas \& Piores, Michael (1990). "Proposal for comparative research on industrial relations and human resource policy and practice", Experts' meeting, OECD, Paris, May 1991.

Kochan, Thomas and Useem, Michael (edit). (1992). "Transforming organizations", Oxford University Press, USA.

Kochan, Thomas, Katz C. Harriz y MacKersie, Robert (1993). "La transformación de las relaciones laborales en los Estados Unidos", Ministerio de Trabajo y Seguridad Social, Madrid.

Kochan, Thomas \& Osterman, Paul (1994). "The mutual gains enterprise, forging a winning partnership among labor, management, and government", Harvard Business Scholl Press, Boston, Massachusetts. 
Kochan Thomas, Locke, Richard and Piore Michael (edit). (1995). "Employment relations in a changing world Economy", MIT Press, Cambridge, Massachusetts, London, Ingland.

Kochan, Thomas, Lansbury, Russell D. y MacDuffie, John Paul (edit), (1997). "After lean production, envolving employment practices in the world auto industry", ILR Press- and Imprint of Cornell University Press, Ithaca and London.

Lamo de Espinosa, E. (1996). Sociedades de cultura, sociedades de ciencia, ensayos sobre la condición moderna. Ediciones Nobel, Madrid.

Locke, Richard \& Kochan, Thomas (1995). "The conclusionn: the transformation labor relations? Kochan Thomas, Locke, Richard and Piore Michael (edit), Employment relations in a changing world Economy, MIT Press, Cambridge, Massachusetts, London, Ingland.

Locke, Richard; Kochan, Thomas y Piore, Michael (1995a). "Replanteamiento del estudio comparado de las relaciones laborales: enseñanzas de una investigación internacional" en Revista Internacional del Trabajo, Vol. 114, No.2, Edit. OIT, pp.157-184, Ginebra.

López, Carmen M. (1998). "Formas de relaciones laborales en Colombia: diversidad y cambio", en Arango, L.G. y López C.M. (comp.), Globalización, apertura económica y relaciones industriales en América Latina, edi- tora, Ces-Universidad Nacional, Bogotá.

López, Carmen M. (1993). Los programas de Control total calidad en Colombia", en: Dombois, Rainer y Pries Ludger (ed.), Modernización Empresarial y trabajo. Experiencias en América Latina y Europa. Nueva Sociedad. Caracas.

López, Carmen M. (1997). Se publicaron cuatro estudios de caso de la industria automotriz y textil, en: Rainer Dombois y Ludger Pries, Las relaciones industriales en el proceso de transformación de América Latina- El Caso de Colombia. Universidad de Bremen, Alemanía.

Offe, Claus (1992). La sociedad del trabajo problemas estructurales y perspectivas de futuro. Madrid, Alianza Editorial.

Ohno, Toichi (1991). El sistema de producción Toyota, más allá de la producción a gran escala. Ediciones Gestión 2000, S.A. Barcelona, España.

Sierra, J. (1990). El obrero soñado. Ensayo sobre el paternalismo industrial (Asturias 1860-1917), Madrid, Siglo XXI.

Weber, Max (1977). Economía y Sociedad. Fondo de Cultura Económica, Bogotá.

Weiss de Belalcázar, Anita (editora). (1997). Modernización industrial: empresas y trabajadores. Universidad $\mathrm{Na}$ cional, Facultad de Ciencias Humanas, Departamento de Sociología, Bogotá. 